Review of
ECONOMICS
and
INSTITUTIONS

INSTITUTIONS
Review of Economics and Institutions

ISSN 2038-1379 DOI 10.5202/rei.v7i2.221

Vol. 7 - No. 2, Autumn 2016 - Article 3

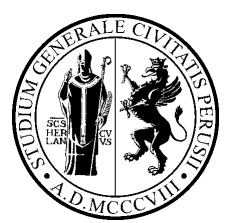

www.rei.unipg.it

\title{
Sources of Labour Productivity Growth at Sector Level in Britain, 1998-2007: A Firm-level Analysis
}

\author{
Geoff Mason $^{凶}$ \\ National Institute of \\ Economic and Social \\ Research, \\ London
}

\author{
Catherine Robinson \\ Kent Business \\ School, \\ University of Kent, \\ Canterbury
}

\author{
Chiara Rosazza \\ Bondibene \\ National Institute of \\ Economic and Social \\ Research, \\ London
}

\begin{abstract}
This article focuses on the sources of labour productivity at a disaggregated sector level using a range of methods for decomposition, including the dynamic OlleyPakes decomposition method introduced by Melitz and Polanec (2015) which offers an alternative approach to the standard dynamic decomposition developed by Foster, Haltiwanger and Krizan (2001). Our findings indicate that, at the firm level, entry and exit played a relatively minor role in improving labour productivity growth in Britain between 1998-2007, although this masks a great deal of variability in the performance of entrants and exitors. A much more significant contribution to labour productivity throughout the period was achieved through the market share growth of incumbent firms with above average productivity. The interpretation of findings is sensitive to underlying assumptions and the approach adopted.
\end{abstract}

JEL classification: L11, 047

Keywords: Productivity decomposition, labour productivity, sector dynamics

This work was based on data from the Business Structure Database and the Annual Business Inquiry, produced by the Office for National Statistics (ONS) and supplied by the Secure Data Service at the UK Data Archive. The data are Crown Copyright and reproduced with the permission of the controller of HMSO and Queen's Printer for Scotland. The use of the data in this work does not imply the endorsement of ONS or the Secure Data Service at the UK Data Archive in relation to the interpretation or analysis of the data. This work uses research datasets which may not exactly reproduce National Statistics aggregates.

We are grateful to the National Endowment for Science, Technology and the Arts (NESTA), London, for financial support of this work. We would especially like to thank Albert Bravo-Biosca for comments and advice at every stage of this work, and also an anonymous referee for helpful comments. Responsibility for all views expressed and remaining errors is ours alone.

Address: 2 Dean Trench Street, Smith Square London, SW1P 3HE United Kingdom (Tel. +44 (0) 207222 7665, Email: G.Mason@niesr.ac.uk).

\section{Recommended Citation}

Mason, G., Robinson, C., Rosazza Bondibene, C. (2016). Sources of Labour Productivity Growth at the Sector Level in Britain, 1998-2007: A Firm-Level Analysis. Review of Economics and Institutions, 7(2), Article 3. doi: 10.5202/rei.v7i2.221.

Retrieved from http://www.rei.unipg.it/rei/article/view/221

Copyright (C) 2016 University of Perugia Electronic Press. All rights reserved 


\section{Introduction}

It is widely believed that a key function of product markets in developed economies is to reallocate resources to their most productive use. Indeed, an Schumpeterian view of the world suggests that continued entry and exit is good for growth. Churn - the entry and exit of higher and lower productivity firms - is expected to lead to higher productivity growth through better resource allocation and lead to a more innovative, efficient, dynamic economy. Using a productivity decomposition approach enables us to consider the interaction between firms, industries and the aggregate economy in achieving productivity growth.

Studies using a variety of country level microeconomic datasets have established that resource reallocation is not simply an external concept but that internal reallocation within and between firms is at least as important as entry and exit. The majority of these studies tend to concentrate on manufacturing and largely present findings at the aggregate level based on plant-level data. In this paper we focus on the sources of labour productivity growth at a disaggregated sector level in the UK between 1998-2007, the period leading up to the 2008-09 recession, explicitly incorporating market service sectors.

In contrast to some of the earlier studies for the UK (and the US), we concentrate on enterprises (firms) rather than on plants. ${ }^{1}$ We initially carry out a static decomposition of labour productivity levels for a single point in time (or rather, the average over three or four single points in time to reduce volatility) following the work of Olley and Pakes (1996). We estimate the extent to which resources become more efficiently allocated over time using this approach by comparing findings over three sub-periods throughout the 1998-2007 period. We then move to a dynamic framework, following Melitz and Polanec (2015), to explore the contributions of firm entry and exit to aggregate productivity changes. The contribution of surviving firms is identified as comprising a component that accounts for changes in the firm-level distribution of productivity and a component that accounts for market share reallocation. We apply this decomposition to British sector-level data for the first time (to our knowledge) and compare our findings with other estimates based on the more widely used decomposition approach put forward by Foster et al. (2001).

The paper is organized as follows. In section 2 we briefly review recent UK evidence on productivity change attributable to resource reallocation. Section 3 describes the respective decomposition methodologies in detail. In Section 4 we discuss the advantages and limitations of the datasets that we make use of. Section 5 presents results on the static decomposition of labour productivity levels. In Section 6 we present results for dynamic decompositions. Section 7 summarizes our main findings.

1 The plant, as a productive unit, is less meaningful in services than in manufacturing. 


\section{Resource Reallocation and Productivity Growth: Recent UK Evidence}

Disney et al. (2003) analyse labour and total factor productivity (TFP) productivity growth in UK manufacturing from 1980 to 1992. Their analysis is based on UK reporting unit data derived from the Annual Respondents Database (ARD) - the micro-data that underlie the published census of production data for the UK and have recently been extended to include service sectors. They identify two main sources of restructuring resulting in higher overall productivity. First, productivity can grow due to changes within existing enterprises (internal restructuring). Second, a process of market selection occurs whereby low productivity establishments exit and are replaced by higher productivity entrants while higher productivity incumbents gain market share (external restructuring). In other words, in line with the previous literature they decompose productivity growth into the parts attributable to growth within surviving establishments and growth due to external restructuring, with the latter consisting of the net effect of entry, exit and changes in market shares of survivors.

Using the Foster, Haltiwanger and Krizan (2001, hereinafter FHK) decomposition approach - discussed in detail in Section 3 below -- Disney et al. (2003) find that internal restructuring and external restructuring both account for around half of labour productivity growth between 1980-1992. The external effect is driven mainly by net entry. When decomposing total factor productivity (TFP) growth, they find that external restructuring accounts for around $80 \%$ of it. An important conclusion drawn from their comparison of labour and TFP growth is that much of the labour productivity growth throughout the 1980s was driven by capital-labour substitution and downsizing.

Harris and Robinson (2005) analyse manufacturing productivity growth in Britain using the FHK decomposition, distinguishing between the contributions of firms that received regional government assistance and those that did not. They analyse plants rather than enterprises for the period 1990-98, focussing on TFP as well as labour productivity. Their analysis indicates that assisted plants make a smaller contribution to labour productivity and a negative contribution to TFP. The most substantial contribution came from the churning of plants (entry and exit) rather than internal reallocation.

Harris and Moffat (2012) extend the analysis to include service sectors 1997-2008, focussing on plant level data. Their decomposition follows the FHK approach and applies an additional regional disaggregation, focussing on Local Economic Partnership (LEP) regions. At the aggregate level, they find that new, more productive plants account for much of the TFP growth. Between-plant reallocations within sectors make the second largest contribution to TFP growth (Harris and Moffat, 2012, p. 10). Their regional analysis indicates that the aggregate picture hides a great deal of regional variation but the importance of plant openings is clear. It is important to note when comparing findings from this and other studies 
that Harris and Moffat focus on plants and thus 'entry' (contributing to TFP growth) may take the form of new plants opened by existing firms as well as the start up of new firms.

\section{Decomposition Methods}

In this section we explore the differences between the main decomposition methodologies used in this paper and assess the relative merits of each approach. We begin with the Olley-Pakes static decomposition, before considering the dynamic decompositions set out by Foster et al. (2001) and Melitz and Polanec (2015). Each method is outlined in detail below. In the static framework, entrants and exitors cannot be directly identified, while the dynamic frameworks, account for the fact that industries are composed of new firms (entrants), dying firms (exitors) and existing firms (incumbents/ continuers).

\subsection{Olley and Pakes Static Decomposition}

This method starts with a definition of aggregate productivity at time $t$ in sector $I$ as a share-weighted average of firm productivity $\pi_{i t}$ :

$$
\Pi_{I t}=\sum_{i} s_{i t} \pi_{i t}
$$

where the shares in each industrial sector $I s_{i t} \geq 0$ sum to 1 . In this context, the share-weighted average sector productivity level in period $t$, $\Pi_{I t}$, can be decomposed into two terms (where the weight is the firm share in total sector employment or sales):

$$
\begin{gathered}
\Pi_{I t}=\bar{\pi}_{I t}+\sum_{i}\left(s_{i t}-\bar{s}_{I t}\right) *\left(\pi_{i t}-\bar{\pi}_{I t}\right)= \\
\bar{\pi}_{I t}+\operatorname{cov}\left(s_{i t}, \pi_{i t}\right)
\end{gathered}
$$

where $\pi$ indicates the logarithm of productivity and $s$ is the firm share in total sector employment or sales. Bars over variables indicate unweighted sectoral averages.

The first term, $\bar{\pi}_{I t}$, is the unweighted average of firm-level productivity at sectoral level. The second term, $\sum_{i}\left(s_{i t}-\bar{s}_{I t}\right) *\left(\pi_{i t}-\bar{\pi}_{I t}\right)=\operatorname{cov}\left(s_{i t}, \pi_{i t}\right)$ is a sample covariance term, between productivity and the sales or employment shares, that reflects the extent to which firms with greater efficiency have greater shares in total sector employment or sales.

The allocative efficiency term is generally interpreted as reflecting whether resource allocation is correlated with firm productivity. That is, if allocative efficiency is positive, firms with above average productivity levels tend to have above average market shares. In other words, a positive allocative efficiency term can be interpreted as an indication of sales or employment shares moving to the more productive firms in the sector. Conversely, allocative efficiency is negative if small firms with 
below average market shares tend to have above average productivity levels. In other words, negative allocative efficiency means that resources are disproportionately allocated towards lower productivity firms in that sector. However, the allocative efficiency term not only captures the extent to which resources are allocated to the most productive firms but also reflects the productivity distribution of firms within the sector, that is, the extent to which there is homogeneity in the sector. Thus, changes over time (as we compare across OP measures) in the allocative efficiency term may be reflective of increased heterogeneity amongst firms, as they become more different in their productivity profiles, or whether resources are reallocated towards higher productive firms. We return to this again when considering the dynamic Olley-Pakes approach below.

The Olley-Pakes method is computationally simple, calculated as the difference between the share-weighted average sector productivity and the unweighted average sectoral productivity. Despite being a static measure, the Olley-Pakes approach can also be used to examine trends in allocative efficiency over time by comparing snapshots based on different annual data. A drawback of the approach is that it does not allow separate analysis of entry and exit of firms over time, which are believed to be a major source of sectoral productivity gain (the result of Schumpeterian churn). However, this is still a powerful tool for considering the degree of allocative efficiency within industries.

\subsection{Foster, Haltiwanger and Krizan Dynamic Decomposition}

The static decomposition of labour productivity helps us to understand the extent to which firms with higher productivity make a greater contribution to sector productivity and therefore the extent to which the sector is technically efficient. However, what it does not allow us to do is consider the allocation of resources as a process, with resources shifting from productive units over time, with firms entering and exiting. We consider now the sector composed of firms that are continuing, entering or exiting the industry and their relative contributions to labour productivity growth between two time periods ( $t=1$ to 2 ).

Similar to the Olley-Pakes static decomposition, the Foster, Haltiwanger and Krizan (FHK) method starts with a definition of aggregate productivity at time $t$ as a share weighted average of firm productivity $\pi_{i t}$ :

$$
\Pi_{I t}=\sum_{i} s_{i t} \pi_{i t}
$$

where the shares in each industrial sector $I s_{i t} \geq 0$ sum to one. However, the variable of interest now is the change in aggregate productivity in sector $I$ over time (from $t=1$ to 2 ) $\Delta \Pi_{I}=\Pi_{I 2}-\Pi_{I 1}$.

Since this productivity change is measured in differences, it is assumed that the underlying productivity measure $\pi_{i t}$ is in logs, so $\Delta \Pi_{I}$ represents a percentage change. The change in the share weighted aggregate productivity of the industry $I$ can be decomposed into five terms: 


$$
\begin{gathered}
\Delta \Pi_{I}=\sum_{i \in C} s_{i 1}\left(\pi_{i 2}-\pi_{i 1}\right)+\sum_{i \in C}\left(s_{i 2}-s_{i 1}\right)\left(\pi_{i 1}-\Pi_{I 1}\right)+\sum_{i \in C}\left(s_{i 2}-s_{i 1}\right)\left(\pi_{i 2}-\pi_{i 1}\right) \\
+\sum_{i \in N} s_{i 2}\left(\pi_{i 2}-\Pi_{I 1}\right)-\sum_{i \in X} s_{i 1}\left(\pi_{i 1}-\Pi_{I 1}\right)= \\
\sum_{i \in C} s_{i 1}\left(\pi_{i 2}-\pi_{i 1}\right)+\sum_{\substack{i \in C \\
+s_{N 2}}}\left(s_{i 2}-\Pi_{i 1}\right)\left(\pi_{i 1}-\Pi_{I 1}\right)+\sum_{i \in C}\left(s_{i 2}-s_{i 1}\right)\left(\pi_{i 2}-s_{X 1}\left(\Pi_{X 1}-\Pi_{I 1}\right)\right.
\end{gathered}
$$

where $I$ indicates the specific sector of the analysis; $i$ indicates firms; time is indicated by $t=1$ to $2, \pi$ indicates $\log$ of labour productivity of firm $i$ and $s$ is the firm share in total sector employment or sales. In our analysis we use employment shares in line with the literature because we are focusing on labour productivity. $C, N$ and $X$ denote the sets of continuing, entering and exiting firms. Continuing firms $(C)$ in sector $I$ are present both at time 1 and time $2 . N$ indicates the set of entering firms in sector I and identifies firms that are present only in period 2. Exiting firms $(X)$ in sector $I$ are present only at time $t=1$.

The first line of the decomposition captures the contribution of continuing firms to productivity changes. The second line captures the contribution of entry and exit and can be re-written in terms of the aggregate shares and productivity levels as: $s_{N 2}\left(\Pi_{N 2}-\Pi_{I 1}\right)-s_{X 1}\left(\Pi_{X 1}-\right.$ $\left.\Pi_{I 1}\right)$ as shown in the fourth line.

In order to interpret this formula, the five terms into which the change in the share-weighted aggregate productivity of the industry has been decomposed can be described as follows.

For the continuing firms $(C)$, the growth rate of the share-weighted average industry I productivity is expressed as the sum of:

1. The share weighted productivity change within the firm (the within component).

2. Two terms that summarize the effect of structural change on aggregate productivity growth among the continuing firms of the industry under consideration:

i) The share cross-term, which is positive if firms with above average productivity also, tends to increase their shares of sales or employment (the between component).

ii) A covariance-type term that is positive if firms with increasing productivity tend to gain in terms of their shares of sales or employment (the cross firm component).

The final two terms of the formula capture the contributions of entering $(N)$ and exiting $(X)$ firms to aggregate productivity growth of industry $I$ :

1. The contribution of an entering ( $N$ ) firm to aggregate productivity change is positive if it has a productivity level above the aggregate productivity in period $t=1, \Pi_{I 1}$. 
2. The contribution of an exiting (X) firm to aggregate productivity growth is positive if its productivity level is below the aggregate productivity in period $t=1, \Pi_{I 1}$.

The entry and exit components summarize these contributions, weighted by the firm share in total industry employment.

\subsection{Olley-Pakes Dynamic Decomposition with Entry and Exit}

Melitz and Polanec (2015) propose an extension of the productivity decomposition method of Olley and Pakes (1996). This extension accounts for the contributions of both firm entry and exit to aggregate productivity changes. It breaks down the contribution of surviving firms into a component accounting for changes in the firm-level distribution of productivity and another accounting for market share reallocations among those firms. They apply their decomposition to the large increases of productivity in Slovenian manufacturing during the 1995-2000 period. They compare and contrast their results with those of other dynamic decompositions such as the FHK methodology.

Again we begin with a definition of aggregate productivity at time $t$ in sector I as a share-weighted average of firm productivity $\pi_{i t}$ :

$$
\Pi_{I t}=\sum_{i} s_{i t} \pi_{i t}
$$

where the shares in each industrial sector $I s_{i t} \geq 0$ sum to 1 . As with the FHK decomposition, the key variable of interest is the change in aggregate productivity over time (from $t=1$ to 2 ) $\Delta \Pi_{I}=\Pi_{I 2}-\Pi_{I 1}$. Again, since this productivity change is measured in differences, it is assumed that the underlying productivity measure $\pi_{i t}$ is in logs, so $\Delta \Pi_{I}$ represents a percentage change.

To understand this decomposition it is necessary to write aggregate productivity in each period of analysis $(t=1$ and $t=2)$ of the aggregate share and aggregate productivity of the three group of firms in industry I: continuers $(C)$, entrants $(N)$ and exitors $(X)$. Continuers are those firms that we observe both at $t=1$ and 2. Entrants are those firms that we observe only in the final period $t=2$.

Finally, we observe exiting firms only in the first period of analysis $t=1$.

$$
\begin{array}{r}
\Pi_{\mathrm{I} 1}=\mathrm{s}_{\mathrm{C} 1} \Pi_{\mathrm{C} 1}+\mathrm{s}_{\mathrm{X} 1} \Pi_{\mathrm{X} 1}=\Pi_{\mathrm{C} 1}+\mathrm{s}_{\mathrm{X} 1}\left(\Pi_{\mathrm{X} 1}-\Pi_{\mathrm{C} 1}\right) \\
\Pi_{\mathrm{I} 2}=\mathrm{s}_{\mathrm{C} 2} \Pi_{\mathrm{C} 2}+\mathrm{s}_{\mathrm{N} 2} \Pi_{\mathrm{N} 2}=\Pi_{\mathrm{C} 2}+\mathrm{s}_{\mathrm{N} 2}\left(\Pi_{\mathrm{N} 2}-\Pi_{\mathrm{S} 2}\right)
\end{array}
$$

where the aggregate productivity of continuers in each period ( $t=1$ and $t=2)$ is simply $\Pi_{C t}=\sum_{i \in C} \frac{s_{i t}}{s_{C t}} \pi_{i t}$, and $s_{C t}=\sum_{i \in C} s_{i t}$. That is, the aggregate productivity of continuers is defined as aggregate productivity in sector $I$ but only restricted to the set of continuing (C) firms. 
It is then possible to write the change in productivity in sector $I \Delta \Pi_{I}=$ $\Pi_{I 2}-\Pi_{I 1}$ in terms of these components and apply the Olley Pakes decomposition (1996) to the set of continuing firms.

$$
\begin{gathered}
\Delta \Pi_{I}=\left(\Pi_{C 2}-\Pi_{C 1}\right)+s_{N 2}\left(\Pi_{N 2}-\Pi_{C 2}\right)+s_{X 1}\left(\Pi_{C 1}-\Pi_{X 1}\right)= \\
\Delta \bar{\pi}_{C}+\Delta \operatorname{cov}_{C}+s_{N 2}\left(\Pi_{N 2}-\Pi_{C 2}\right)+s_{X 1}\left(\Pi_{C 1}-\Pi_{X 1}\right)
\end{gathered}
$$

The first line decomposes the aggregate productivity change into components for the three groups of firms in industry $I$ : continuers $(C)$, entrants $(N)$ and exitors $(X)$. The second line rewrites the first term in Equation 1; the Olley-Pakes decomposition is applied to the group of continuers, disentangling the change in labour productivity into two components: the unweighted change in average productivity of continuers, $\Delta \bar{\pi}_{\mathrm{C}}$ and the change in the covariance between market share and productivity for continuers, $\Delta \operatorname{cov}_{C}$, (i.e. the change in the allocative efficiency term in the Olley-Pakes decomposition, which is induced by market share reallocations or changes in sector dispersion, discussed above). Notice that using this methodology implies the following:

1. Entrants $(N)$ generate positive productivity growth only if they have higher productivity $\Pi_{N 2}$ than the remaining (surviving) firms $\Pi_{C 2}$ in the same time period when entry takes place $(t=2)$.

2. Exiting firms $(X)$ generate positive productivity growth only if they have lower productivity $\Pi_{X 1}$ than the remaining (surviving) firms $\Pi_{C 1}$ in the same time period when exit takes place $(t=1)$.

This interpretation of the terms differs from the FHK decomposition where the contributions of entrants and exits are evaluated relative to the aggregate productivity level in Year 1. Under the FHK approach, entrants (N) generate positive productivity growth only if they have higher productivity than all firms in period $t=1 \quad \Pi_{I 1}$ (where $I=C+X$ ). Similarly, exiting firms $(X)$ generate positive productivity growth only if they have lower productivity than all firms in period $t=1 \quad \Pi_{I 1}$ (where $I=C+X$ ).

Compared to the Melitz and Polanec approach, the reference group productivity level in the FHK decomposition will necessarily lead to a bias in measuring the contributions of both groups (and especially entrants). This is because $\Pi_{C 2}$ is higher than $\Pi_{I 1}$ for two reasons: firstly, it excludes firms which exited in period 1 (assuming exiting firms have on average a lower productivity change), and secondly, it captures any productivity improvements of continuers between periods 1 and 2 . Thus, under the FHK approach the measured contribution of entrants will be biased upwards and the contributions of continuers and exiting firms will be biased downwards.

As we show below in Section 6, Melitz and Polanec's choice of reference group productivity levels for entrants and exiting firms is more intuitively appealing than the FHK approach and enables us to look in some detail at 
what is going on within the groups of entrant and exiting firms. In particular, we are able to identify the following subgroups of interest:

1. Surviving firms over the two years of analysis $(C)$;

2. Year 2 entrants with higher average labour productivity levels than continuing firms in year $2\left(N_{\text {high }}\right)$;

3. Year 2 entrants with lower average labour productivity levels than continuing firms in year $2\left(N_{\text {low }}\right)$;

4. Year 1 exits with higher average labour productivity levels than continuing firms in year $1\left(X_{\text {high }}\right)$;

5. Year 1 exits with lower average labour productivity levels than continuing firms in year $1\left(X_{\text {low }}\right)$.

In terms of the effects of entry and exit on sector I productivity growth, only categories 2 and 5 will have positive effects on sector productivity growth between Years 1 and 2. Our productivity growth decomposition will therefore be equal to:

$$
\begin{gathered}
\Delta \Pi_{\mathrm{I}}=\Delta \bar{\pi}_{\mathrm{C}}-\Delta \operatorname{cov}_{\mathrm{C}}+s_{\mathrm{N}_{\mathrm{high}} 2}\left(\Pi_{\mathrm{N}_{\mathrm{high}} 2}-\Pi_{\mathrm{C} 2}\right)+s_{\mathrm{N}_{\mathrm{low}} 2}\left(\Pi_{\mathrm{N}_{\mathrm{low}} 2}-\Pi_{\mathrm{C} 2}\right) \\
+s_{\mathrm{X}_{\mathrm{high}} 1}\left(\Pi_{\mathrm{C} 1}-\Pi_{\mathrm{X}_{\mathrm{high}} 1}\right)+s_{\mathrm{X}_{\text {low }} 1}\left(\Pi_{\mathrm{C} 1}-\Pi_{\mathrm{X}_{\text {low }} 1}\right)
\end{gathered}
$$

This disaggregation enables us to see the extent to which heterogeneity in entry and exit is obscured by the aggregation procedure. Results from the static decomposition of levels of productivity are presented in Section 5 and findings in relation to the dynamic decompositions are presented in Section 6.

\section{Firm-level Data Sources: The Annual Respondents Database and the Business Structure Database}

\subsection{Data Description}

Two datasets are available for the analysis of firm-level growth and productivity in the UK. ${ }^{2}$ The Annual Respondents Database (ARD) draws on successive years of the Annual Business Survey (ABS), formerly the Annual Business Inquiry (ABI), which is a detailed financial survey of all firms with over 250 employees but only samples, those firms that employ less than 250 employees. While data are available for manufacturing back

2 Other data sources are available, for example, FAME Company Accounts. However the coverage is not thought to be as comprehensive as the official business register data collected by the Office for National Statistics. 
to 1974 , total economy data (i.e. including services) are only available from $1997 .^{3}$

An alternative source is the Business Structure Database (BSD) which consists of linked snapshots of the Inter-Departmental Business Register (IDBR) which is the sampling frame for the ABS. This is a census of all firms that are registered for Value Added Tax (VAT) and Pay As You Earn (PAYE) income taxation in Great Britain, thus it contains the majority of industrial activity. The BSD is more limited in terms of variables available than the ABS/ARD in that it only contains information on sales and employees. We have chosen to work with both surveys, but primarily using the ARD, with the BSD as a source of supplementary data when the ARD is incomplete. In assembling data for analysis, we excluded non-market services where inputs are difficult to relate to outputs in the conventional sense. Both datasets are owned by the ONS and are now accessed under special conditions through the Data Archive virtual environment, the Secure Data Service.

\subsubsection{Unit of Analysis}

The business register data for the UK are stored in 4 levels. Local unit data are akin to the plant level. This contains the most basic information on the unit, generally its main industrial activity and employment. Data are stored at reporting unit level that can be seen as lines of business as defined by each firm. While financial information is collected and stored at this level, it is not a legal requirement that firms maintain their composition over time. Therefore, it is entirely possible that reporting units can change the local units that they report for. The third level is the enterprise reference level. This is an economically meaningful unit that remains consistent over time. The final unit is the ultimate owner (WOWENT), which aggregates firms up to holding company level.

For this study we take the enterprise as the unit of analysis (classified as ENTREF in the IDBR). A limitation of doing so is that analysis based on clearly defined geography is more complicated. A number of the decomposition studies that have been carried out, particularly for the UK, have been based on plant level data (i.e. units below the enterprise level). As a unit of business within manufacturing, the plant makes intuitive sense but this is arguably less relevant in the context of service sectors. Moreover, because financial data are not collected at the local unit level, any data need to be spread back from reporting units on the basis of employment information, thus in principle assuming the same level of productivity across all the local units which form part of each reporting unit. In the majority of cases, firms are single site enterprises and so the plant is equivalent to the firm or enterprise. The ARD contains on average around 50,000 enterprises in any single year.

Some exclusions apply to the British data, including parts of agriculture and financial intermediation, so data are not strictly whole economy figures. 


\subsubsection{Sampling Issues}

A problem faced when using the ARD is that smaller firms are surveyed on a sample basis and therefore can exit the dataset not only as a result of business closure but also because of sampling rules. In Section 4.2.1 below, we elaborate on how this is dealt with. Complications arise not just because of difficulties in defining entry and exit components but because the decomposition approaches in this study rely on market shares. However, while a large number of enterprises 'drop out' of the ARD on the basis of employment size due to sampling, these account for a relatively small proportion of overall output. In terms of our decomposition, we include all firms available in the ARD, although we acknowledge that our coverage of the under 100 employee enterprises is less than complete because of the issues highlighted. This may raise the question why the ARD is used rather than the BSD for the decomposition analysis. The advantage of the ARD is that it includes value added information, a more appropriate measure for labour productivity. In our analysis below we consider the sensitivity of the findings to whether the $\mathrm{BSD}$ or the ARD is analyzed.

\subsection{Data Construction}

The period of analysis is 1998 to 2007 . More recent data are available but, at the time of analysis, there were a number of unresolved coding issues with some post-2008 data, particularly with respect to the enterprise reference number (entref), our chosen unit of analysis. Moreover, given that the financial crisis began to take hold in 2008 there is something of a structural break around this time. We therefore have 10 years for our analysis and we are able to split this into 3 periods for the static decomposition and into 2 equal sub-periods for the dynamic decomposition.

Data are stored at the reporting unit level, so our first task was to construct enterprise-level data. This required a number of assumptions, starting with the allocation of enterprises to particular industries. In most cases, firms operated in a single area of the Standard Industrial Classification (SIC). However multisite organizations could often be allocated to two or more industries. We assumed that the firm was operating chiefly in the industry in which it had the largest employment share. Employment in the ARD and the BSD is measured as a headcount. There is no information on hours worked or on the quality of workers employed, although information on the wage bill is available. Finally, we note that financial data used throughout this paper have been deflated using 2-digit SIC deflators derived from EUKLEMS, which are based on PPI series from ONS. ${ }^{4}$

4 For information on the EUKLEMS database, see: http:/ / www.euklems.net/ 


\subsubsection{False Entrants and Exits}

Dynamic decompositions rely on firm level data at two points in time $(t$ and $t+k$ ). Combining these two time periods, we note that there are three categories of firms - those that exist throughout the period (continuers), those that exist in $t$ but not in $t+k$ (exitors) and those that exist by $t+k$ but were not in the data at point $t$ (entrants). However, because data in the ARD are sampled at the smaller end of the size distribution, there will be situations when firms without information for period $t+k$ should not be classed as exiting firms since they will reappear in future years. Conversely, there are firms for which data are missing for the period $t$, but which were simply not sampled in that year and so are not genuine entrants.

In order to deal with false entrants and exits, we supplement the ARD with information from the BSD. Because the BSD is to all intents and purposes a census of firms, we match firms classified as births and deaths into the BSD to check their status, which is determined by whether or not employment and sales information are available in the year in question, whether or not the firm is classified as having died or been born before or after $t$ or $t+k$, and whether or not the firm is classed as "active". If we are able to locate firms, the question then is, how can we impute information on labour productivity for these firms in $t$ or $t+k$ using BSD data on employment and sales to estimate productivity growth. On occasion, we find that employment information is missing in the ARD and in these instances we are able to use the BSD data to supplement the ARD. Another issue we have noticed is that the ARD may flag firms as being continuers when the BSD suggests they have exited. This may in part be an issue of timing since the BSD data lags the ARD. We take the view that the ARD survey data is the most accurate data available.

Table 1 shows the percentage of surviving, entering and exiting firms in the ARD data by sector. We can see that on average the share of entering and exiting firms is about $16 \%$ with the percentage of entering firms being slightly higher than the percentage of exiting firms. However, the table shows some heterogeneity across sectors.

\subsubsection{Industrial Classification Issues}

Industry groups in the analyses are determined largely by sample sizes and meaningful industrial groupings. We favor a 24-sector split that broadly corresponds to sub-sectors of the 2003 SIC (standard industrial classification), although to address sample size issues, we have merged some sectors. For the static decompositions, a more detailed industry breakdown has been used and we average our scores over three years to smooth any outliers (there are fewer sample size problems when entrants and exits are not identified).

Another complication is that firms can change industries over time. Because the decomposition analysis relies on firms' shares in sector totals, it is difficult to accommodate firms switching industries. We therefore assume that firms remain in the industry to which they were initially 
allocated in period $t$. If the SIC code is missing (as it will be for entrants between $t$ and $t+k$ ), then the SIC for $t+k$ is defined according to the value it has in that year. If both SICs are missing, we use the SIC supplied by the BSD.

Table 1. Enterprises in the ARD from 1998 to 2007 (Unweighted)

\begin{tabular}{l|ccc|c}
\hline Industry & $\begin{array}{c}\% \\
\text { Surviving }\end{array}$ & $\begin{array}{c}\% \\
\text { Entering }\end{array}$ & $\begin{array}{c}\% \\
\text { Exiting }\end{array}$ & Total \\
\hline Mining and Quarrying, Electricity, gas and water supply & 78.14 & 9.56 & 12.30 & 732 \\
Manufacture of food, beverages and tobacco & 85.63 & 4.43 & 9.94 & 2,707 \\
Manufacture of textile and leather products & 88.43 & 3.41 & 8.15 & 2,343 \\
Manufacture of wood products & 89.35 & 4.50 & 6.15 & 911 \\
Manufacture of pulp, paper and printing & 85.35 & 4.71 & 9.94 & 3,653 \\
Manufacture of chemicals & 87.74 & 4.15 & 8.11 & 1,591 \\
Manufacture of rubber & 88.25 & 3.83 & 7.92 & 1,906 \\
Manufacture of non-metallic minerals & 85.47 & 4.65 & 9.88 & 1,184 \\
Manufacture of basic metals and fabricated metal & 90.44 & 4.12 & 5.44 & 4,929 \\
products & & & & \\
Manufacture of machinery and equipment NEC & 90.59 & 3.21 & 6.20 & 3,113 \\
Manufacture of electrical and optical equipment & 88.38 & 3.74 & 7.87 & 3,340 \\
Manufacture of transport equipment & 87.99 & 4.76 & 7.24 & 1,491 \\
Manufacturing NEC & 88.81 & 6.08 & 5.10 & 2,038 \\
\hline Construction & 80.97 & 11.95 & 7.08 & 10,308 \\
\hline Sale, maintenance and repair of motor vehicles & 86.95 & 5.86 & 7.19 & 6,314 \\
Wholesale trade & 87.71 & 5.89 & 6.40 & 15,524 \\
Retail trade & 83.36 & 8.75 & 7.90 & 16,006 \\
Hotels and restaurants & 77.25 & 12.34 & 10.41 & 6,400 \\
Transport and storage & 85.96 & 7.66 & 6.38 & 5,877 \\
Post and telecommunication & 65.47 & 22.75 & 11.78 & 611 \\
Real estate & 78.46 & 14.51 & 7.03 & 3,046 \\
Renting of machinery and equipment & 81.70 & 10.44 & 7.85 & 1,197 \\
Computing and related activities & 74.47 & 16.05 & 9.48 & 3,376 \\
R\&D and other business services & 79.55 & 12.56 & 7.89 & 16,571 \\
\hline Total & 83.87 & 8.50 & 7.63 & 115,168 \\
\hline Source: ARD data, various years, authors' calculations & & & & \\
& & & & \\
\hline
\end{tabular}

\subsubsection{Population Weighting}

As discussed above, the ARD comprises a census of firms with 250 or more employees and a sample of firms with employment below this level. Thus, the data under-represent the smaller end of the employment size distribution. To correct the decomposition to reflect a firm's share in the actual total sector employment (or output), the data could be population weighted. In earlier studies using the ARD data some have used population weights (Disney et al. 2003 and Harris and Robinson, 2005) and others have not (Oulton, 2000). In this report we do not use population weights because of concerns about volatility arising from the relatively large weights attached to firms with fewer than 250 employees in the ARD. It is also unclear how appropriate it would be to use ARD cross-sectional weights for a dynamic decomposition sample which has been supplemented with BSD information to try and correct for false 
entrants and exits (see Section 4.2.1). One concern about using unweighted data is that the extent of entry and exiting may be overstated (Oulton, 2000). Correcting for false entrants and exits using BSD information may alleviate this concern.

By way of sensitivity test, and specifically to check the extent to which our decomposition results have been affected by not using population weights, we also compare decomposition estimates based on ARD data (with labour productivity defined as real value added per employee) with estimates based on BSD data (with labour productivity defined as real sales per employee). As reported in Mason et al. (2014, Appendix A2), this comparison shows little evidence of bias in terms of our general findings for dynamic decompositions for the periods under consideration.

However, the same is not true for comparisons of static decomposition estimates of allocative efficiency over time, with the BSD-based estimates casting doubt on the representativeness of ARD-based findings when micro-firms (those with fewer than 10 employees) are included in the analysis without using population weights. By contrast, the BSD-based estimates are more in line with static decomposition results for firms with ten or more employees. Accordingly, in Section 5 below, we present static decomposition results only for firms with ten or more employees. ${ }^{5}$ These firms account for just over $80 \%$ of total value added in UK market sectors. ${ }^{6}$

\subsection{Market Share Indicators: Employment vs. Output}

Another element of uncertainty in conducting the decomposition is whether the market share weights used in the decomposition analysis should be defined in terms of output or employment. In this study our main results are based on using employment shares as weights (rather than output shares) since employment is theoretically more appropriate to a labour productivity measure of performance. In Mason et al. (2014, Appendix A1), we present an extended discussion of the choice of appropriate market share weights together with some sensitivity tests where output shares are used instead of employment shares. These tests show that our main findings are largely robust to the use of output weights.

\section{Static Decomposition Estimates}

Table 2 presents estimates of the Olley-Pakes static decomposition for firms with ten or more employees in Manufacturing, Services and Other Production sectors between 1998 and 2007. In this analysis market shares have been defined in terms of employment shares while aggregation up to

5 Note that other work at NIESR making use of population weights confirms a marked drop in allocative efficiency among firms with ten or more employees between 1999-2001 and 2005-2007 (Riley and Rosazza Bondibene, 2016, Figure 4.1.2).

6 Refers to UK non-financial business economy in 2013. Source: Derived from ONS, Annual Business Survey, 2013 Revised results [released 11 June 2015]. 
broad industry group and total economy levels has been carried out on a bottom-up basis (that is, aggregating over three digit sector-level decompositions). We discuss below the results of sensitivity tests using different approaches to both the definition of market shares and to aggregation procedures.

Table 2. Static Olley-Pakes Decomposition at Total Economy and Broad Industry Group Levels, 1998-2007, Analyzed by Sub-period, Firms with 10 or more Employees

\begin{tabular}{lcccc}
\hline \multicolumn{1}{c}{ Industry } & \multicolumn{2}{c}{ Average Productivity } & Allocative & \\
& Weighted & Unweighted & Efficiency & N [\#] \\
\hline 1998-2000 & & & & \\
\hline Total Economy & 3.215 & 2.978 & 0.237 & 78,027 \\
Manufacturing & 3.550 & 3.388 & 0.163 & 28,533 \\
Services & 3.026 & 2.744 & 0.282 & 43,691 \\
Other Production & 3.968 & 3.918 & 0.050 & 5,803 \\
\hline 2001-2003 & & & & \\
\hline Total Economy & 3.214 & 3.028 & 0.186 & 82,299 \\
Manufacturing & 3.527 & 3.388 & 0.139 & 27,664 \\
Services & 3.055 & 2.856 & 0.200 & 48,109 \\
Other Production & 3.952 & 3.739 & 0.212 & 6,526 \\
\hline 2004-2007 & & & 0.161 & \\
\hline Total Economy & 3.314 & 3.153 & 0.170 & 31,341 \\
Manufacturing & 3.682 & 3.512 & 0.167 & 56,005 \\
Services & 3.167 & 3.001 & 0.050 & 6,999 \\
Other Production & 4.001 & 3.951 & & \\
\hline
\end{tabular}

Source: ARD various years, authors' calculations (firms with 10 or more employees; employment weights; bottom-up aggregation).

In each row of Table 2, the employment-weighted average log labour productivity level (Column 1) corresponds, as shown in Equation 2, to the sum of the unweighted average log labour productivity level (Column 2), and the allocative efficiency measure (Column 3). The last column $\mathrm{N}$ reports the number of firms in each specific cell. The exercise is repeated for three groups of years (1998-2000, 2001-2003 and 2004-2007) where the measures are smoothed to reduce any distortion due to outliers. These estimates provide us with snapshots of allocative efficiency in different time periods that can be compared to give some indication of trends over time.

The allocative efficiency term can be interpreted as the difference in percentage terms between weighted and unweighted productivity levels in the sectors under consideration. Thus, to give an example for the period 1998-2000, allocative efficiency among firms with ten or more employees in the total economy was $23.7 \%$, that is, allocative efficiency is $23.7 \%$ higher than it would have been if all firms had an equal market share. When we look at results by broad industry group, we note that this estimate of allocative efficiency derives mainly from Services $(28 \%)$ where it is substantially higher than the allocative efficiency scores for Manufacturing and Other Production (16\% and 5\%, respectively).

Note that the allocative efficiency measure at total economy level tends to fall over time and this largely reflects a decline in allocative efficiency in 
Service sectors. In the case of Manufacturing sectors, the positive allocative efficiency measure is slightly higher in 2004-07 than in 1998-2000. Figure 1 illustrates the dominant impact of Services on trends in allocative efficiency over time. As shown below in Section 5.3, the sharp fluctuations in allocative efficiency in Other Production sectors were largely driven by developments in electricity, gas and water. However, the Other Production sectors are too small in employment terms to have much effect on the total economy measure of allocative efficiency.

Figure 1. Allocative Efficiency at Total Economy and Broad Industry Group Levels, 1998-2007, Analyzed by Sub-period, Firms with 10 or more Employees

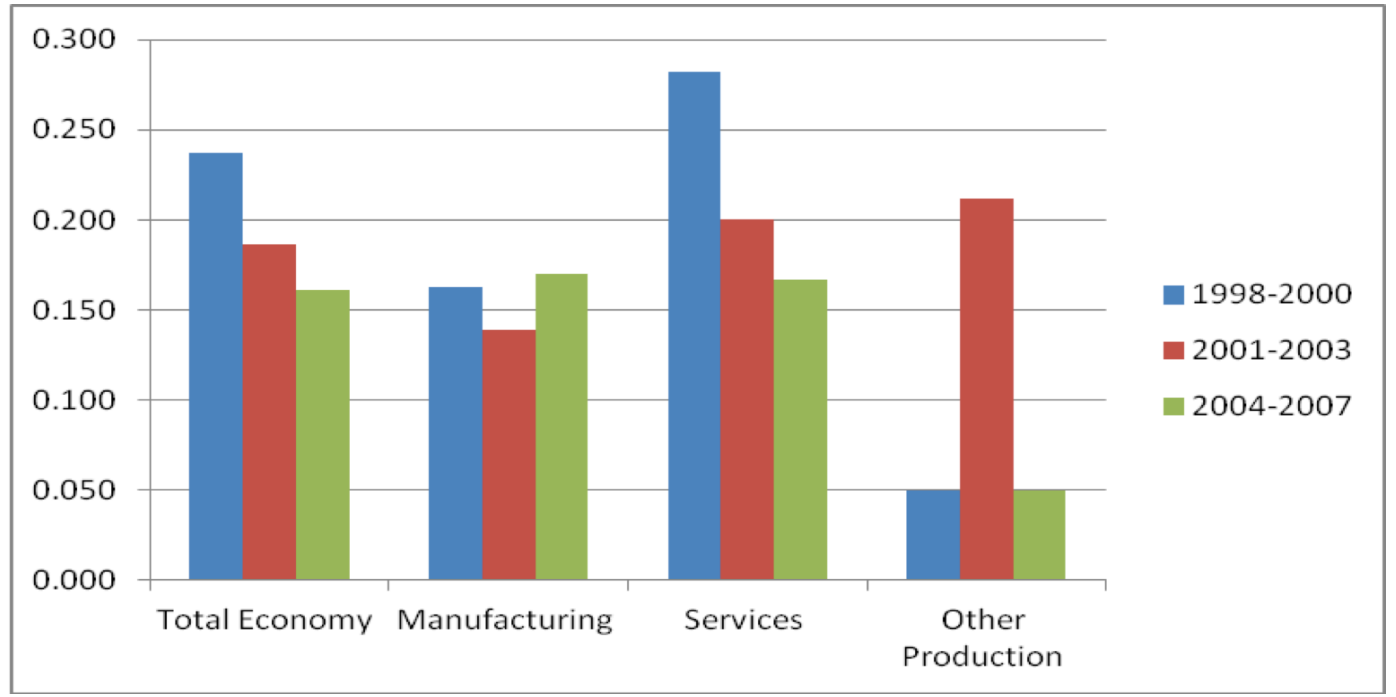

Source: ARD various years, authors' calculations (firms with 10 or more employees; employment weights; bottom-up aggregation).

\subsection{Static Decompositions Using Output Share Weights}

An alternative to defining market shares in terms of each firm's share of total sector employment is to use output shares instead. Results for static decompositions using gross value added (GVA) share weights are presented in Table 3 and the differences between the two weighting choices are illustrated in Figure 2. In general, using GVA weights increases estimated levels of labour productivity and boosts the perceived contribution of larger firms which makes a big difference to estimated allocative efficiency in Other Production sectors that are notably capital intensive. But, overall, the main trends identified when using employment weights -declining allocative efficiency over time in Services and the total economy- are still identified when GVA weights are used as indicators of market share. 
Table 3. Static Olley-Pakes Decomposition of Labour Productivity Using GVA Share Weights (1998-2007), Firms with 10 or more Employees

\begin{tabular}{|c|c|c|c|c|}
\hline \multirow{2}{*}{ Industry } & \multicolumn{2}{|c|}{ Average Productivity } & \multirow{2}{*}{$\begin{array}{l}\text { Allocative } \\
\text { Efficiency }\end{array}$} & \multirow{2}{*}{$\mathbf{N}[\#]$} \\
\hline & Weighted & Unweighted & & \\
\hline \multicolumn{5}{|l|}{$1998-2000$} \\
\hline Total Economy & 3.702 & 2.978 & 0.724 & 78,027 \\
\hline Manufacturing & 3.938 & 3.388 & 0.550 & 28,533 \\
\hline Services & 3.525 & 2.744 & 0.781 & 43,691 \\
\hline Other Production & 4.667 & 3.918 & 0.750 & 5,803 \\
\hline \multicolumn{5}{|l|}{ 2001-2003 } \\
\hline Total Economy & 3.699 & 3.028 & 0.671 & 82,299 \\
\hline Manufacturing & 3.947 & 3.388 & 0.559 & 27,664 \\
\hline Services & 3.545 & 2.856 & 0.69 & 48,109 \\
\hline Other Production & 4.675 & 3.739 & 0.936 & 6,526 \\
\hline \multicolumn{5}{|l|}{ 2004-2007 } \\
\hline Total Economy & 3.804 & 3.153 & 0.651 & 94,345 \\
\hline Manufacturing & 4.113 & 3.512 & 0.601 & 31,341 \\
\hline Services & 3.658 & 3.001 & 0.657 & 56,005 \\
\hline Other Production & 4.701 & 3.951 & 0.750 & 6,999 \\
\hline
\end{tabular}

Figure 2. Allocative efficiency at total economy and broad industry group levels, 1998-2007, analysed by sub-period, firms with 10 or more employees, using GVA share weights

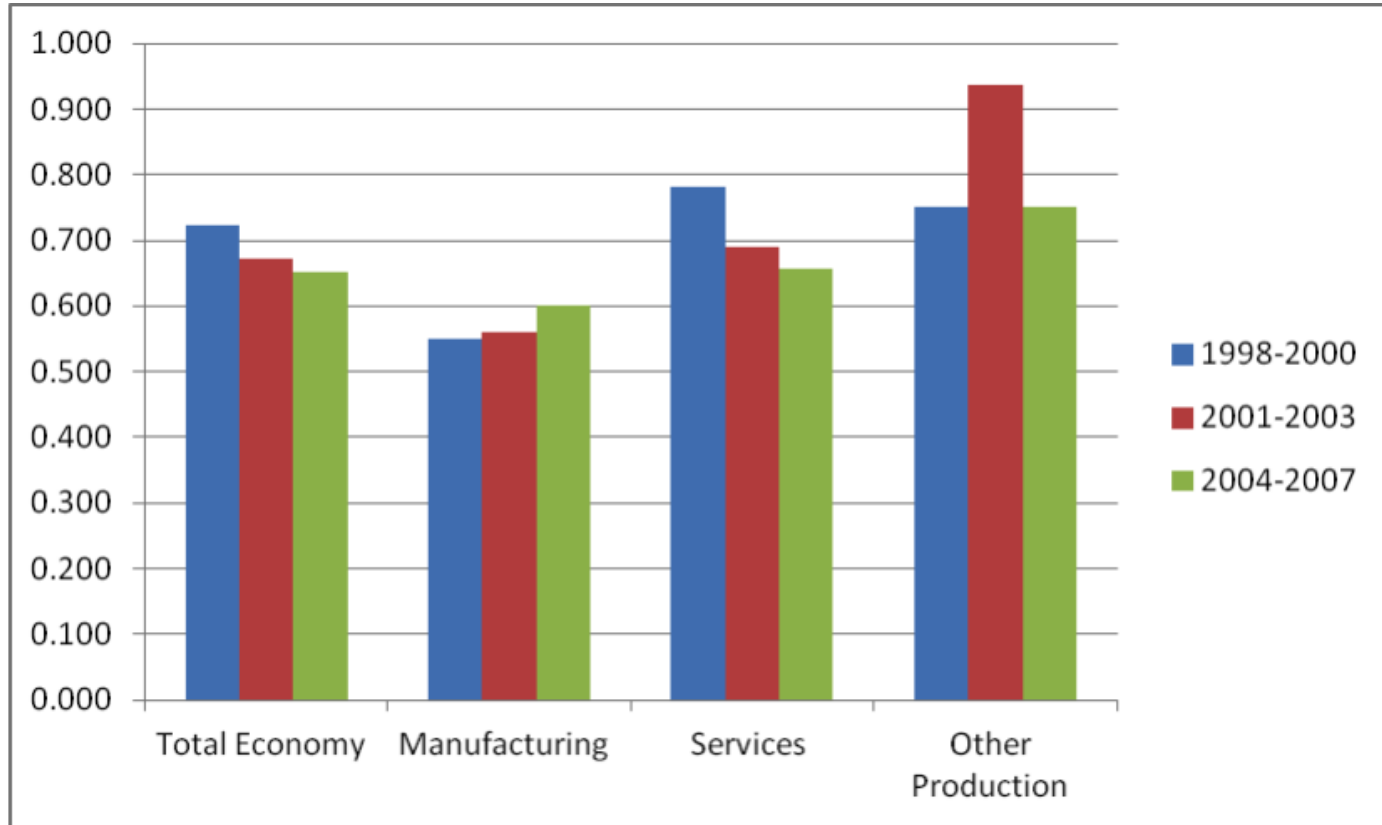

Source: ARD various years, authors' calculations (firms with 10 or more employees; GVA weights; bottom-up aggregation). 


\subsection{Aggregation to Broad Sector Group and Total Economy Levels: Top-down versus Bottom-up Approaches}

In Table 2 we presented results in which aggregation up to broad industry group and total economy levels had been carried out on a bottom-up basis (that is, aggregating over three digit sector-level decompositions, using employment shares as weights). An alternative approach would be a top-down procedure in which decompositions are carried out directly at broad industry group and total economy levels using measures of aggregate output and employment that have been derived by summing across firm-level data on output and employment within each industry group and the total economy.

Estimates using a top-down approach are shown in Table 4 and Figure 3 and display considerable differences in absolute levels of unweighted labour productivity at broad sector group and total economy levels compared to those found using the bottom-up approach to aggregation (see Table 1 and Figure 1). These differences show that aggregation procedures are important and can influence findings. However, in the present case we still observe declining allocative efficiency over time in services and the total economy (for firms with ten or more employees) when using a top-down approach to aggregation just as was found when using a bottom-up approach.

Table 4. Static Olley Pakes decompositions of labour productivity, 1998-2007, firms with 10 or more employees, top-down approach to aggregation

\begin{tabular}{lcccc}
\hline \multicolumn{1}{c}{ Industry } & \multicolumn{2}{c}{ Average Productivity } & Allocative & \\
& Weighted & Unweighted & Efficiency & N [\#] \\
\hline 1998-2000 & & & & \\
\hline Total Economy & 3.215 & 3.149 & 0.066 & 78,027 \\
Manufacturing & 3.466 & 3.266 & 0.200 & 28,533 \\
Services & 3.026 & 3.015 & 0.010 & 43,691 \\
Other Production & 4.023 & 3.586 & 0.437 & 5,803 \\
\hline 2001-2003 & & & & \\
\hline Total Economy & 3.214 & 3.221 & -0.007 & 82,299 \\
Manufacturing & 3.529 & 3.343 & 0.186 & 27,664 \\
Services & 3.056 & 3.100 & -0.044 & 48,109 \\
Other Production & 3.952 & 3.598 & 0.354 & 6,526 \\
\hline 2004-2007 & & & & \\
\hline Total Economy & 3.316 & 3.368 & -0.053 & 94,345 \\
Manufacturing & 3.682 & 3.471 & 0.211 & 31,341 \\
Services & 3.169 & 3.268 & -0.099 & 56,005 \\
Other Production & 4.000 & 3.713 & 0.286 & 6,999 \\
\hline
\end{tabular}

Source: ARD various years, authors' calculations (firms with ten or more employees; employment weights; top-down aggregation). 
Figure 3. Allocative efficiency at total economy and broad sector group levels, 1998-2007, firms with ten or more employees, top-down approach to aggregation

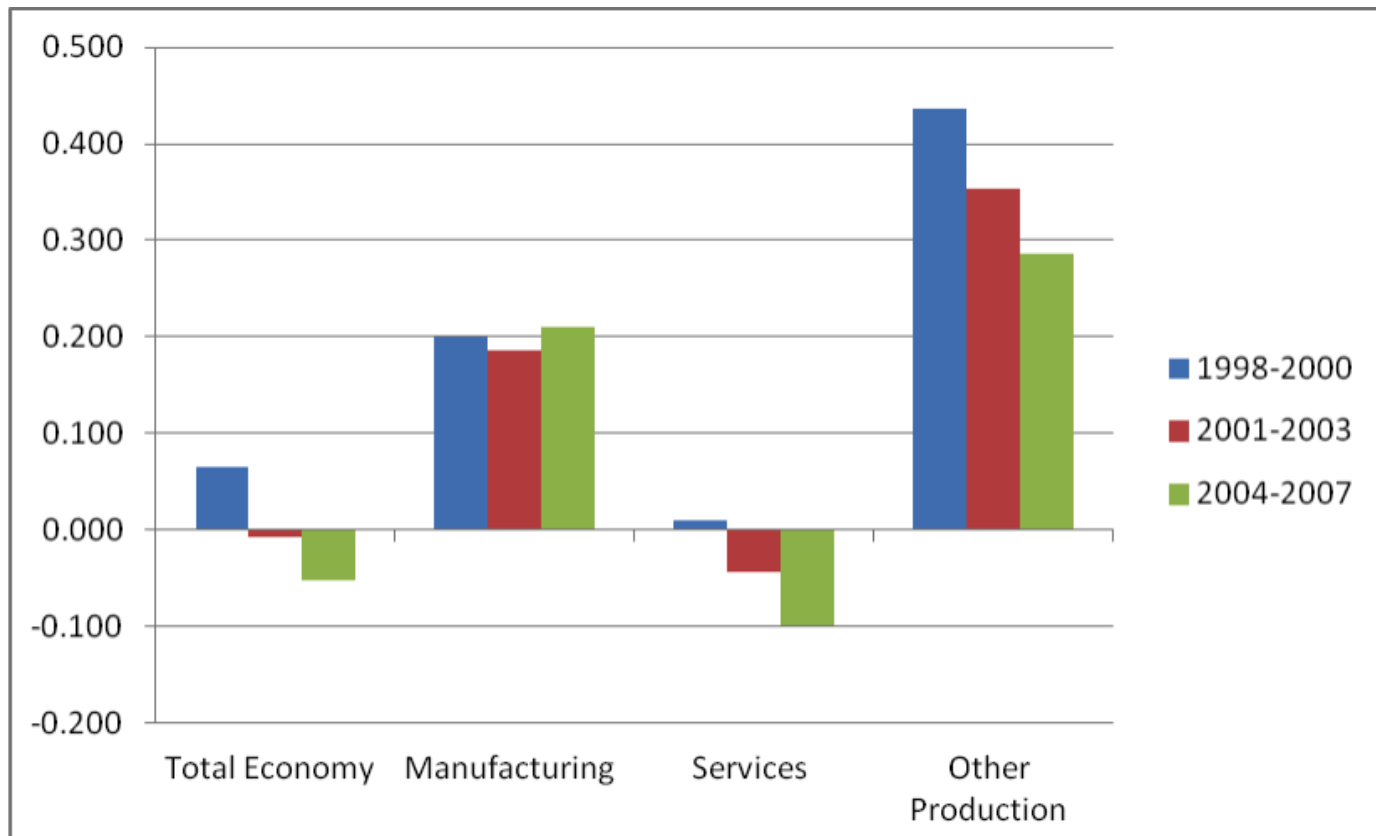

Source: ARD various years, authors' calculations (firms with 10 or more employees; employment weights; top-down aggregation).

\subsection{Trends in Allocative Efficiency at Disaggregated Sector Level}

Disaggregated results for the static Olley-Pakes decomposition of labour productivity using employment share weights are shown in Figure 4 (A and B) and presented in detail in Appendix A. Recall that allocative efficiency in the total economy for firms with ten or more employees was estimated to have fallen from $23.7 \%$ in the $1998-2000$ period to $16.1 \%$ between 2004-07 (Figure 1), with the bulk of the decline occurring in the broad services industry group. The disaggregated results show wide variation between service sectors in the extent to which this reduction in allocative efficiency occurred, with much of the decline concentrated in the retail and hotels and catering sectors (Figure 4B). By contrast, in some transport and business service sectors, allocative efficiency actually increased over the same period. There was also some diversity in manufacturing where allocative efficiency grew more rapidly over this period in chemicals and non-metallic mineral products than other sectors and actually declined slightly in sectors such as food and drink manufacturing and rubber and plastics. Among other production sectors, allocative efficiency declined in mining and quarrying between 1998-2007 and fluctuated sharply between sub-periods in electricity, gas and water (Figure 4A). 
Figure 4A. Trends in Allocative Efficiency, 1998-2007, Analyzed by Sector, Firms with 10 or more Employees: Manufacturing and other Production Sectors

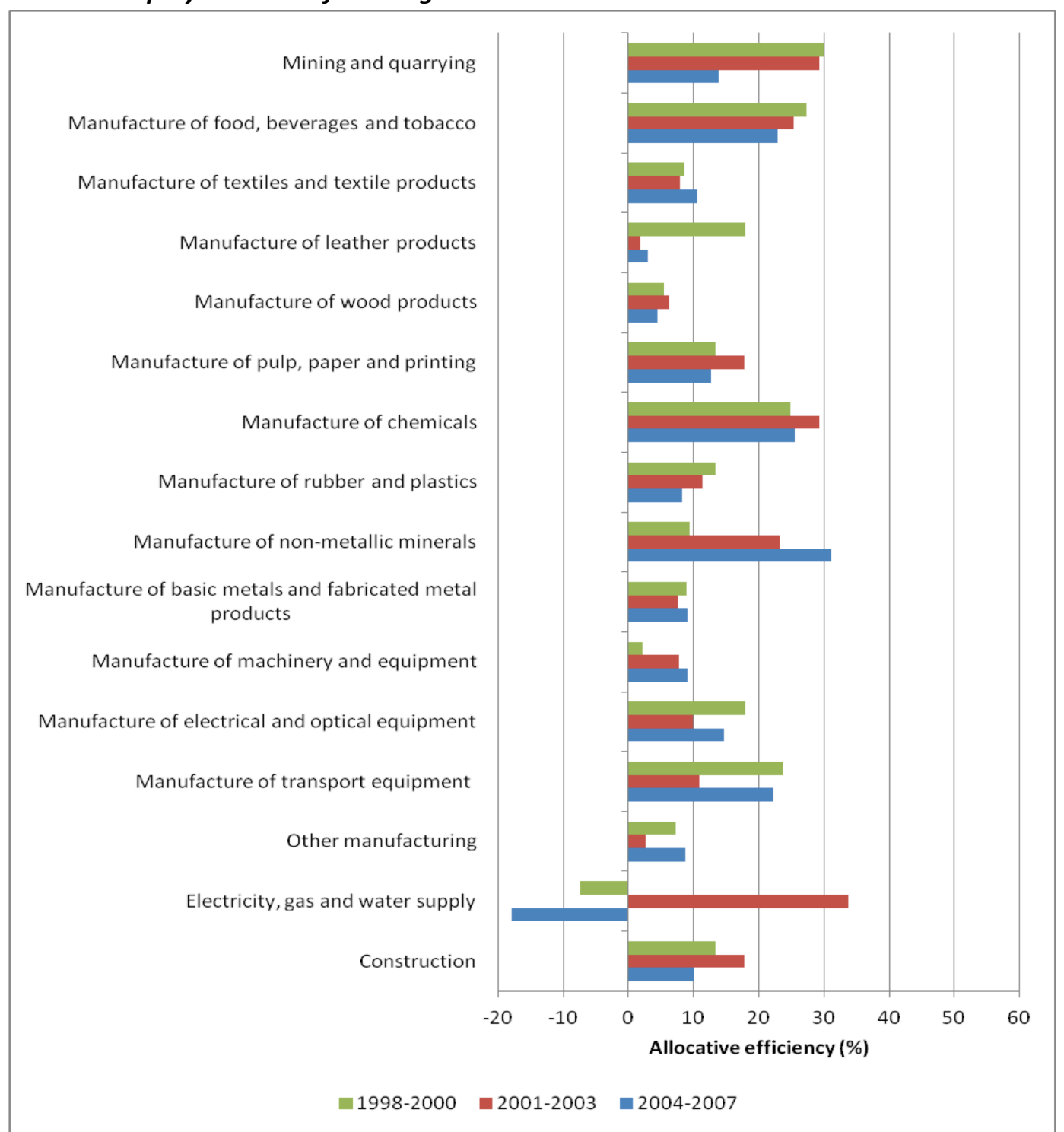

Source: ARD, authors' calculations (firms with ten or more employees; employment weights; bottom-up aggregation). Detailed estimates are shown in Appendix, Tables A1-A3. 
Figure 4B. Trends in Allocative Efficiency, 1998-2007, Analyzed by Sector, Firms with 10 or more Employees: Service Sectors

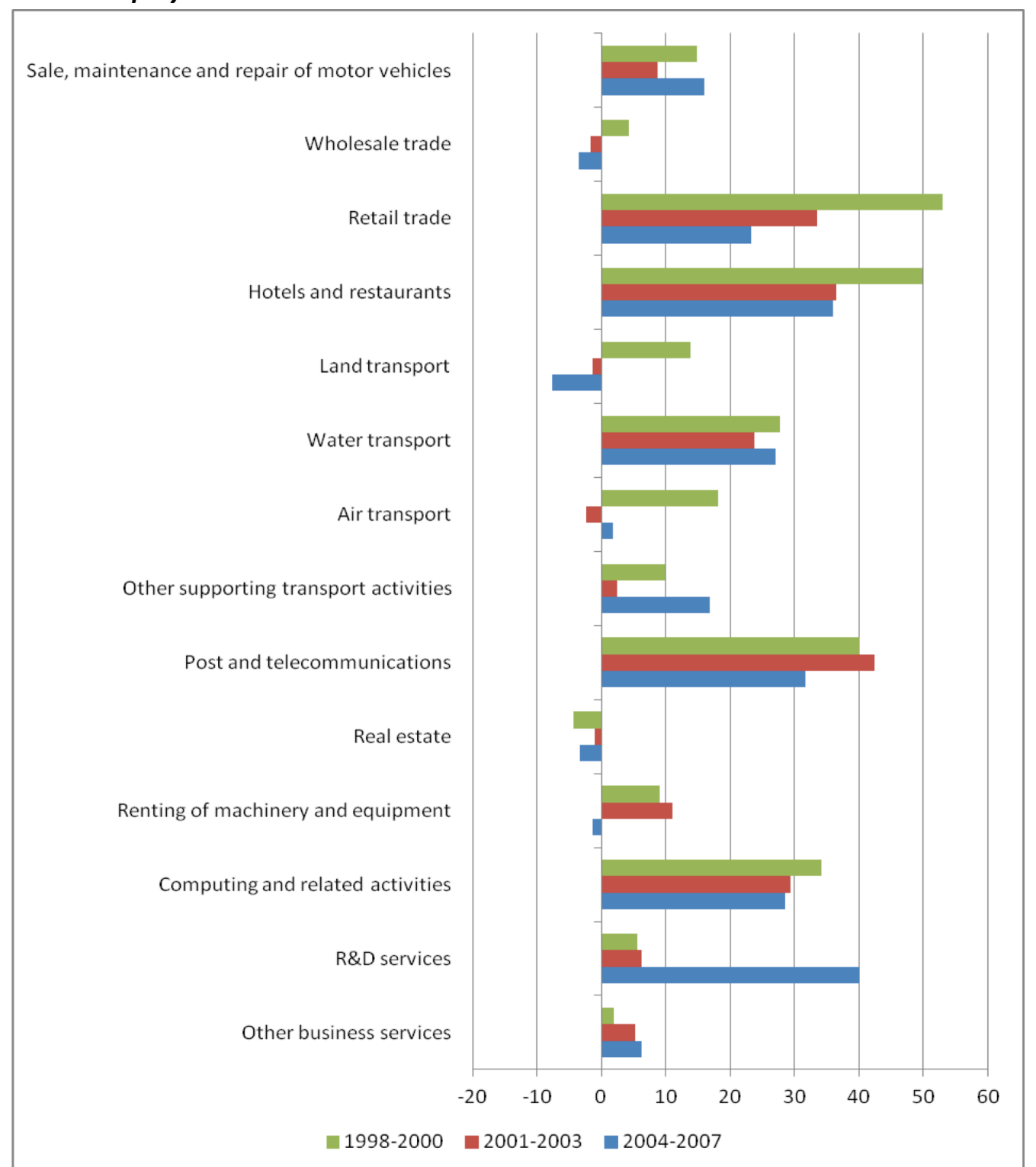

Source: ARD, authors' calculations (firms with ten or more employees; employment weights; bottom-up aggregation). Detailed estimates are shown in Appendix, Tables A1-A3.

Appendix Tables A4 to A6 show detailed results for static Olley and Pakes decompositions for firms with ten or more employees using a top-down approach to aggregation in which decompositions are computed directly for each of the broad sectors listed in the tables rather than taking a weighted average of the productivity decompositions of smaller sectors. Any differences in allocative efficiency measures between Tables A1 to A3 and Tables A4 to A6 could be due to the reallocation of resources from one sector to another, although the results do not seem to differ a great deal. This is most likely because we are looking at a relatively short period of time, without a significant structural 
readjustment of the economy requiring reallocation from one sector to another.

Taking an overview of all these static decomposition results, one possible explanation for declining allocative efficiency in some sectors is that competitive pressures are not sufficiently strong to ensure that the most productive firms gain market share at the expense of less productive firms. In these circumstances less productive firms may not only be able to survive but may even be able to increase their shares of total employment in their sectors.

Another possibility in some sectors is that rapid changes in technologies and products may enable more innovative firms - many of them new entrants to the market - to implement new ideas and technologies that improve their productivity performance. However, it may take time for these firms to build up their market shares and meanwhile less productive firms may still be able to maintain relatively large market shares rather than be forced to cut back heavily on employment or come under pressure to exit the market. In this scenario firm-level variation in innovation and technological progress should eventually, through market competition, contribute to reallocation of resources from less productive uses to more productive uses. However, this process is likely to unfold in different ways and on different timescales in each sector. In order to shed more light on inter-sectoral differences of this kind, we now turn to alternative approaches to analyzing productivity growth that take account of industry dynamics including the entry of new firms and the exit of other firms.

\section{Dynamic Decomposition Estimates}

Dynamic decompositions rely on snapshots of data at two points in time ( $t 1$ and $t 2$ ). In this paper data for 1998, 2002, 2003 and 2007 have been used. We present findings for the 10 years period (1998-2007) and two 5 years sub-periods, beginning with a discussion of the total economy level (subject to the omissions that have been noted in Section 4 above), using the Foster, Haltiwanger and Krizan (FHK) and Melitz and Polanec (MP) decomposition methodologies. All dynamic decompositions use the top-down approach to aggregation rather than the bottom-up approach discussed in Section 5 because of restrictions on the use of estimates derived from small sample sizes relating to entrants and exitors in three-digit sectors. Because of concern about the reliability of data from micro firms, we report decompositions both including and excluding firms with fewer than 10 employees. Theoretically, including small firms is preferred, since our methodologies are based on each firm's productivity being weighted according to its 'size' (either output or employment weighted). Excluding them is therefore likely to bias our findings. Moreover, a practical consideration is the drop in sample sizes when small firms are excluded, particularly when we explore the decompositions at more detailed levels of sectoral disaggregation. 


\subsection{Aggregate Results}

In order to assess the effectiveness and impact of resource reallocation at sector level, it is useful to draw on elements of both the FHK and MP decompositions. As noted in Section 3.3, the FHK decomposition can be criticized on the grounds that the productivity levels of entrants (which we observe only at the end of the period) and exitors (which we observe only at the start of the period) are both benchmarked against average productivity for all firms observed in the initial period. The MP decomposition offers a more appropriate reference productivity level when assessing the contribution of entry and exit to aggregate productivity performance. In the MP decomposition, the productivity levels of entering and exiting firms are referenced against the average productivity of continuing firms at the times when entry and exit, respectively, take place. But although the MP approach is more useful for evaluation of the effects of new entrants and exiting firms, it has drawbacks with regard to resource reallocation within and between continuing firms. In particular, the second component of the MP distribution (which measures the changing relationship between market share and productivity among continuing firms) does not just capture resource reallocation but also moves in line with changes in productivity performance at firm level even when no reallocation of resources has occurred (for example, when rapid productivity growth takes place within large firms). By contrast, the FHK decomposition offers a clearer way to assess the relative importance of productivity changes within firms and productivity changes which can be attributed to external restructuring.

Tables 5A and 5B compare the MP and FHK results at the aggregate economy level. The tables present the aggregate decompositions over three time periods (the full period and two five year periods). The final column shows the change in labour productivity over each period and is therefore the same for each set of decompositions, regardless of the method used.

FHK-based estimates suggest that, between 1998-2007, internal restructuring within continuing firms contributed an estimated 20 percentage points ( $\mathrm{pp}$ ) to growth in average labour productivity in the total economy but this was partly offset by negative growth of $-4 \%$ in the combined effects of external restructuring so that productivity in the total economy grew by an estimated 16 pp over this period.

When we look more closely at the different components of external restructuring (comprising reallocation of resources between continuing firms as well as entry and exit), it is clear that the main negative effect is coming from the cross-firm component, suggesting that many firms with increasing productivity have not succeeded in gaining increased market shares. This could occur if firms with increasing productivity see their employment share reducing over the period, which implies labour shedding (or firm employment growth slower than sector growth). 
Table 5.A: Decomposition of Labour Productivity, 1998-2007, MP method

\begin{tabular}{|c|c|c|c|c|c|}
\hline \multirow[b]{2}{*}{ MP method } & \multicolumn{2}{|c|}{ Surviving Firms } & \multicolumn{2}{|c|}{ Firms } & \multirow{2}{*}{$\begin{array}{c}\text { Change in share } \\
\text { weighted } \\
\text { average } \\
\text { productivity }^{\text {level }^{c}}\end{array}$} \\
\hline & $\begin{array}{c}\text { Unweighted average } \\
\text { firm level } \\
\text { productivity }^{a}\end{array}$ & $\begin{array}{l}\text { Allocative } \\
\text { efficiency }^{b}\end{array}$ & Entering & Exiting & \\
\hline \multicolumn{6}{|l|}{ 1998-2007 } \\
\hline all firms & 0.01 & 0.14 & -0.01 & 0.02 & 0.16 \\
\hline excluding firms $<10$ employees & 0.09 & 0.05 & -0.01 & 0.02 & 0.15 \\
\hline \multicolumn{6}{|l|}{$1998-2002$} \\
\hline all firms & -0.07 & 0.07 & 0.00 & 0.02 & 0.01 \\
\hline excluding firms $<10$ employees & -0.01 & 0.01 & 0.00 & 0.02 & 0.01 \\
\hline \multicolumn{6}{|l|}{$2003-2007$} \\
\hline all firms & 0.03 & 0.10 & 0.00 & 0.00 & 0.12 \\
\hline excluding firms $<10$ employees & 0.06 & 0.07 & 0.00 & 0.00 & 0.12 \\
\hline
\end{tabular}

Table 5.B: Decomposition of Labour Productivity, 1998-2007, FHK method

\begin{tabular}{|c|c|c|c|c|c|c|}
\hline \multirow[b]{2}{*}{ FHK method } & \multicolumn{3}{|c|}{ Surviving Firms } & \multicolumn{2}{|c|}{ Firms } & \multirow{2}{*}{$\begin{array}{l}\text { Change in share } \\
\text { weighted average } \\
\text { productivity level }^{c}\end{array}$} \\
\hline & Within & Between & Cross & Entering & Exiting & \\
\hline \multicolumn{7}{|l|}{ 1998-2007 } \\
\hline all firms & 0.20 & 0.15 & -0.20 & 0.00 & 0.01 & 0.16 \\
\hline excluding firms $<10$ employees & 0.19 & 0.12 & -0.17 & 0.00 & 0.02 & 0.15 \\
\hline \multicolumn{7}{|l|}{$1998-2002$} \\
\hline all firms & 0.07 & 0.10 & -0.17 & 0.00 & 0.02 & 0.01 \\
\hline excluding firms $<10$ employees & 0.07 & 0.07 & -0.14 & 0.00 & 0.02 & 0.01 \\
\hline \multicolumn{7}{|l|}{$2003-2007$} \\
\hline all firms & 0.15 & 0.11 & -0.13 & 0.00 & 0.00 & 0.12 \\
\hline excluding firms $<10$ employees & 0.14 & 0.10 & -0.11 & 0.00 & 0.00 & 0.12 \\
\hline
\end{tabular}

Note. It is not possible to sum the two periods to arrive at the full period levels because they do not overlap. Thus, we do not include the change between 2002 and 2003. ${ }^{a} \Delta \bar{\pi}_{C} ;{ }^{b} \Delta \operatorname{cov}_{C} ;{ }^{c} \Delta \Pi_{I}$.

Source: ARD and BSD various years, authors' calculations (employment share weights used).

In both the FHK and MP approaches, the estimated contributions of entry and exit to productivity growth are relatively small. However, when entrants and exitors are disaggregated between firms with above-average productivity and those with below-average productivity, applying the MP decomposition, it is notable that the small net effects of entry and exit conceal a more interesting pattern of events below the surface (Table 6). First, high-productivity entrants make a positive contribution of $1.5 \mathrm{pp}$ to aggregate productivity growth but this is more than cancelled out by the $-2.3 \mathrm{pp}$ contribution of new firms that show relatively low productivity levels when they first start up. Second, it is notable that the exit of low-productivity firms adds an average $7.7 \mathrm{pp}$ to annual productivity growth between 1998-2007 but this is offset to a considerable extent by the $-5.9 \mathrm{pp}$ contribution of firms that exit with above average productivity levels.

Thus the small estimated net effects of entry and exit hide two phenomena of potentially great interest to policy-makers. First, a sizeable 
proportion of new entrants, about $47 \%$ of all new entrants between 1998-2007, appear to need time to develop and improve their performance before they will contribute positively to aggregate productivity performance. Second, many firms that fail to survive (40\% of all exitors between 1998-2007) are above-average performers in terms of productivity: their inability to survive may reflect market imperfections such as funding constraints or anti-competitive practices.

Table 6. MP Decomposition with Entry and Exit above and below Average Labour Productivity, 1998-2007

\begin{tabular}{|c|c|c|c|c|c|c|c|}
\hline & \multicolumn{2}{|c|}{ Surviving Firms } & \multicolumn{2}{|c|}{ Entering Firms } & \multicolumn{2}{|c|}{ Exiting Firms } & \multirow{2}{*}{$\begin{array}{c}\text { Change in share } \\
\text { weighted } \\
\text { average } \\
\text { productivity }^{\text {level }^{c}}\end{array}$} \\
\hline & $\begin{array}{c}\text { average firm } \\
\text { level } \\
\text { productivity }^{a}\end{array}$ & $\begin{array}{l}\text { Allocative } \\
\text { efficiency }^{b}\end{array}$ & $\begin{array}{l}\text { Above } \\
\text { avg. LP }\end{array}$ & $\begin{array}{c}\text { Below } \\
\text { avg. LP }\end{array}$ & $\begin{array}{l}\text { Above } \\
\text { avg. LP }\end{array}$ & $\begin{array}{l}\text { Below } \\
\text { avg. LP }\end{array}$ & \\
\hline \multicolumn{8}{|l|}{ 1998-2007 } \\
\hline Total Economy & 0.010 & 0.140 & 0.015 & -0.023 & -0.059 & 0.077 & 0.16 \\
\hline$\%$ share & \multicolumn{2}{|c|}{83.87} & 3.90 & 4.60 & 2.94 & 4.69 & \\
\hline \multicolumn{8}{|l|}{ 1998-2002 } \\
\hline Total Economy & -0.070 & 0.070 & 0.01 & -0.012 & -0.020 & 0.037 & 0.01 \\
\hline$\%$ share & \multicolumn{2}{|c|}{92.95} & 2.04 & 2.52 & 1.00 & 1.49 & \\
\hline \multicolumn{8}{|l|}{ 2003-2007 } \\
\hline Total Economy & 0.030 & 0.100 & 0.004 & -0.008 & -0.028 & 0.026 & 0.12 \\
\hline$\%$ share & \multicolumn{2}{|c|}{94.79} & 1.70 & 1.92 & 0.76 & 0.83 & \\
\hline
\end{tabular}

Note. ${ }^{a} \Delta \bar{\pi}_{C} ;{ }^{b} \Delta \operatorname{cov}_{C} ;{ }^{c} \Delta \Pi_{I}$.

Source: ARD and BSD various years, authors' calculations (employment share weights used)

Turning to the sensitivity of our findings to the exclusion of firms with fewer than 10 employees, Table 7 reveals the effects on sample sizes of such exclusion. Whilst sample sizes are substantial enough to present aggregate results, a detailed sectoral breakdown becomes less feasible, partly because of disclosure issues and partly because the absence of small firms makes any findings less economically meaningful.

Table 7. Cell Counts of all Firms (Including and Excluding 10 Employees)

\begin{tabular}{|c|c|c|c|c|}
\hline & Surviving & Entering Firms & Exiting Firms & Total \\
\hline \multicolumn{5}{|l|}{ all firms } \\
\hline 1998-2007 & 96,590 & 9,786 & 8,792 & 115,168 \\
\hline 1998-2002 & 125,554 & 6,156 & 3,362 & 135,072 \\
\hline 2003-2007 & 118,262 & 4,527 & 1,975 & 124,764 \\
\hline \multicolumn{5}{|c|}{ excluding firms with $<10$ employees } \\
\hline 1998-2007 & 50,734 & 3,425 & 5,508 & 59,667 \\
\hline 1998-2002 & 67,660 & 2,006 & 2,276 & 71,942 \\
\hline 2003-2007 & 67,426 & 1,084 & 1,699 & 70,209 \\
\hline
\end{tabular}

Source. ARD and BSD various years, authors' calculations, Employment share weights used.

Figure 5 shows the FHK decomposition for the total economy with and without firms with fewer than 10 employees. The results suggest that the FHK decomposition is generally less sensitive to the exclusion of small firms than is the MP decomposition. We note also considerable 
heterogeneity across the periods. In the FHK-based estimates the within component remains virtually the same between the full sample and the truncated sample. The categories most clearly affected by the change in sample are the cross and between components, both of which appear noticeably smaller when small firms are excluded.

Figure 5. FHK Decomposition, 1998-2007, Total Economy, Including and Excluding Firms with Fewer than 10 Employees

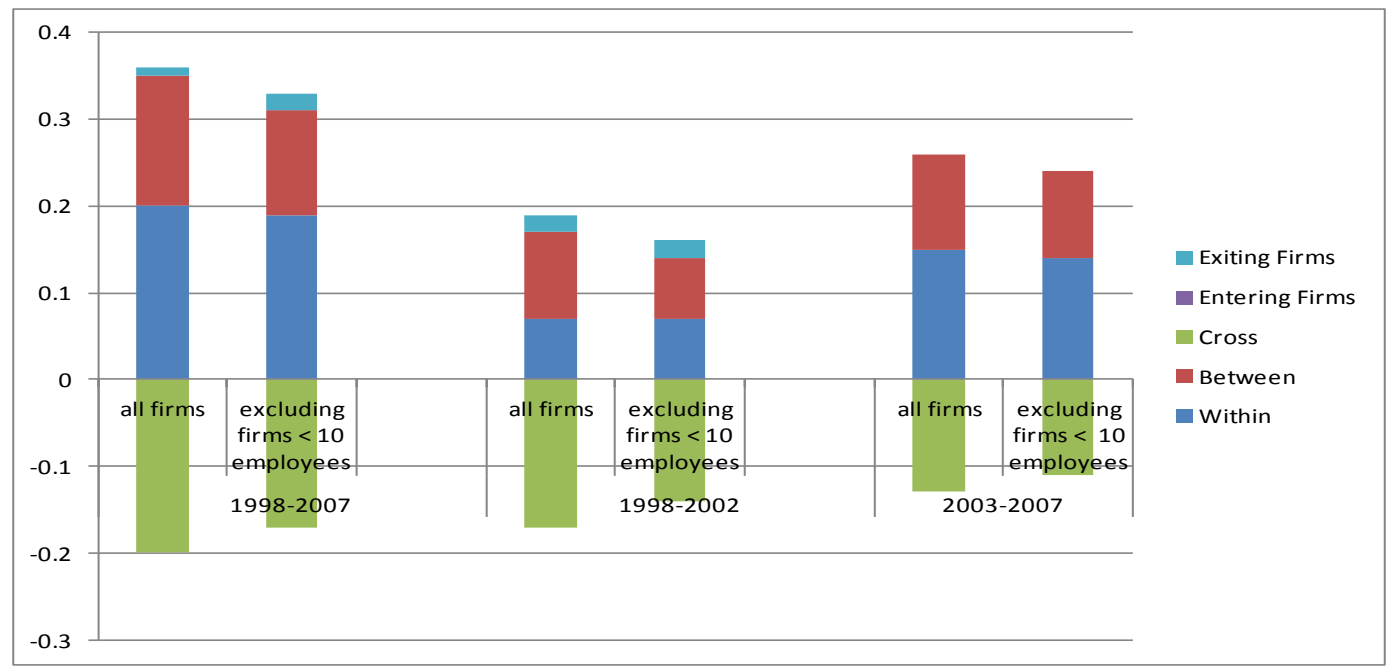

Source: ARD and BSD various years, authors' calculations, Employment share weights used.

As Figure 6 shows, using the MP decomposition results in the same overall level of change in labour productivity over the truncated sample as for the full sample (as expected given that smaller firms account for relatively small market shares).

Figure 6. Melitz - Polanec Decomposition, 1998-2007, Total Economy, Including and Excluding Firms with fewer than 10 Employees

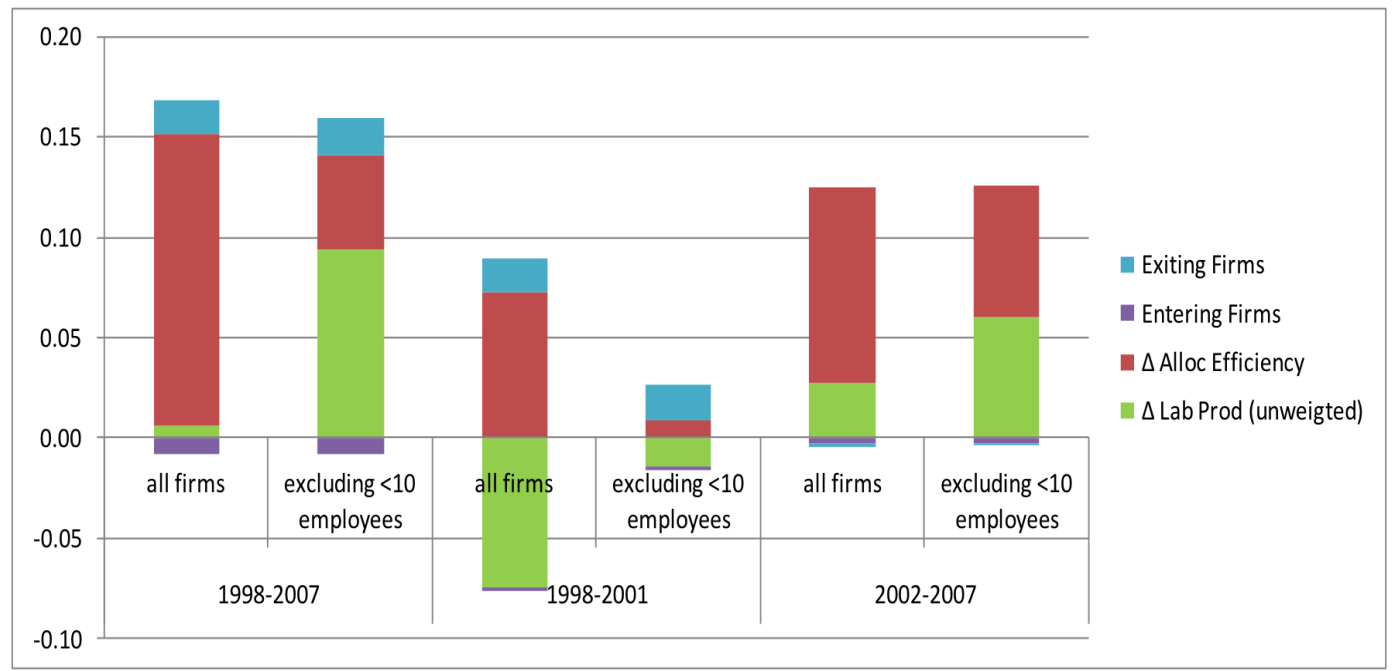

Source: See Figure 5. 
However, excluding the small firms yields a very different pattern in the sources of productivity change in the MP-based results, with the change in allocative efficiency (increasingly productive firms becoming larger) becoming noticeably less important when we exclude small firms. By contrast, the net effects of entry and exit in the MP approach do not change greatly when small firms are excluded. According to further analysis (not reported here), the story regarding entrants and exitors with above/below average productivity levels also remains broadly the same regardless of whether small firms are included in or excluded from the sample.

\subsection{Dynamic Decompositions: Detailed Sector Results}

In view of the different strengths of the FHK and MP decompositions described above, we present two sets of disaggregated sector-level estimates, one using the FHK decomposition to examine resource reallocation within and between continuing firms; and the other using the MP decomposition to explore how new entrants and exiting firms divide between above-average and below-average productivity performers.

Figure 7A shows FHK-based estimates that suggest that labour productivity growth between 1998-2007 ranged from 40\%+ in textiles, electrical and optical equipment, transport equipment and post and telecommunications to $-12 \%$ in food and drink manufacturing and combined mining/utilities. In all manufacturing sectors except for non-metallic minerals, productivity growth attributable to productivity changes within continuing firms tended to outweigh the contribution made by external restructuring. Here external restructuring involving continuing firms is defined as the sum of productivity changes arising from reallocation of resources between continuing firms (as some of them gain market share and others lose it) and the 'cross-firm' component which is positive if firms with increasing productivity tend to gain in terms of market share, or negative if market share tends to be gained by firms with decreasing productivity. The highest rates of within-firm productivity growth occurred in textiles, electrical and optical equipment and transport equipment manufacturing.

By contrast with manufacturing sectors, in the construction sector the effects of within-firm productivity changes were matched by the impact of external restructuring. And in the combined mining and utilities sectors the effects of within-firm productivity changes were completely outweighed by negative productivity effects arising from external restructuring (Figure 7A).

In all service sectors within-firm productivity changes predominated over the effects of external restructuring on continuing firms. In four service sectors external restructuring had negative effects on productivity: hotels and restaurants, transport and storage, real estate and other business services (Figure 7B).

Turning to MP-based estimates of the effects of firm entry and exit on labour productivity growth at detailed sector level, the results show marked differences between sectors. 
Figure 7A. Decomposition of Growth in Avg. Labour Productivity Growth Attributable to Resource Reallocation within and between Continuing firms, 1998-2007, Analyzed by Sector, FHK decomposition: Manufacturing and other Production Sectors.

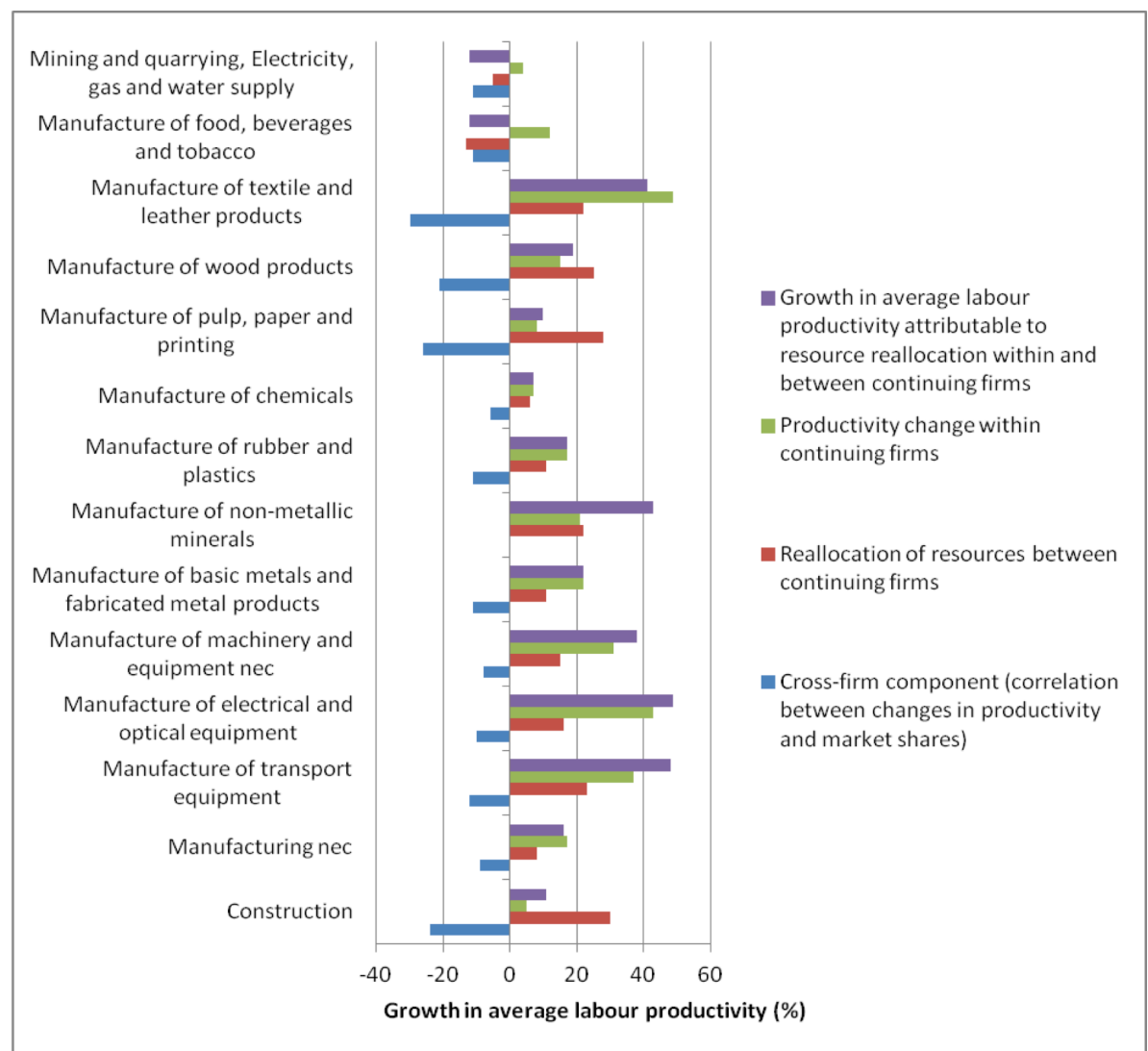

Source: ARD, authors' calculations. Detailed estimates are shown in Appendix Table B9.

In 14 out of 24 sectors, the net effect of firm entry on sectoral productivity between 1998-2007 was small and negative, in line with the total economy, while in six sectors the productivity impact of net entry was small and positive.

In four sectors net entry had a negative effect on productivity that was conspicuously greater than the economy-wide average (Figures 8A and 8B). i) Real estate services: where new entrants with relatively low productivity levels depressed average labour productivity by -9 pp over the period, only partly offset by the 2 pp contribution of high-productivity entrants. ii) Computer services: -6 pp contribution from low-productivity entrants; 1 pp contribution from high-productivity entrants. iii) Other business services: -5 pp contribution from low-productivity entrants; $3 \mathrm{pp}$ contributions from high-productivity entrants. iv) Transport equipment: -3 pp contribution from low-productivity entrants; 1 pp contribution from high-productivity entrants.

In these sectors the relatively high contribution made by low-productivity entrants presumably reflects above average ease of entry for weaker performers. Further research would be useful to explore the 
extent to which such entrants survive and manage to improve their performance over time. In 16 out of 24 sectors net exits had a positive effect on productivity performance between 1998-2007, reflecting high rates of departure for low-productivity firms as would be expected in competitive market conditions.

Figure 7B. Decomposition of Growth in Avg. Labour Productivity Growth Attributable to Resource Reallocation within and between Continuing firms, 1998-2007, Analyzed by Sector, FHK decomposition: Service Sectors

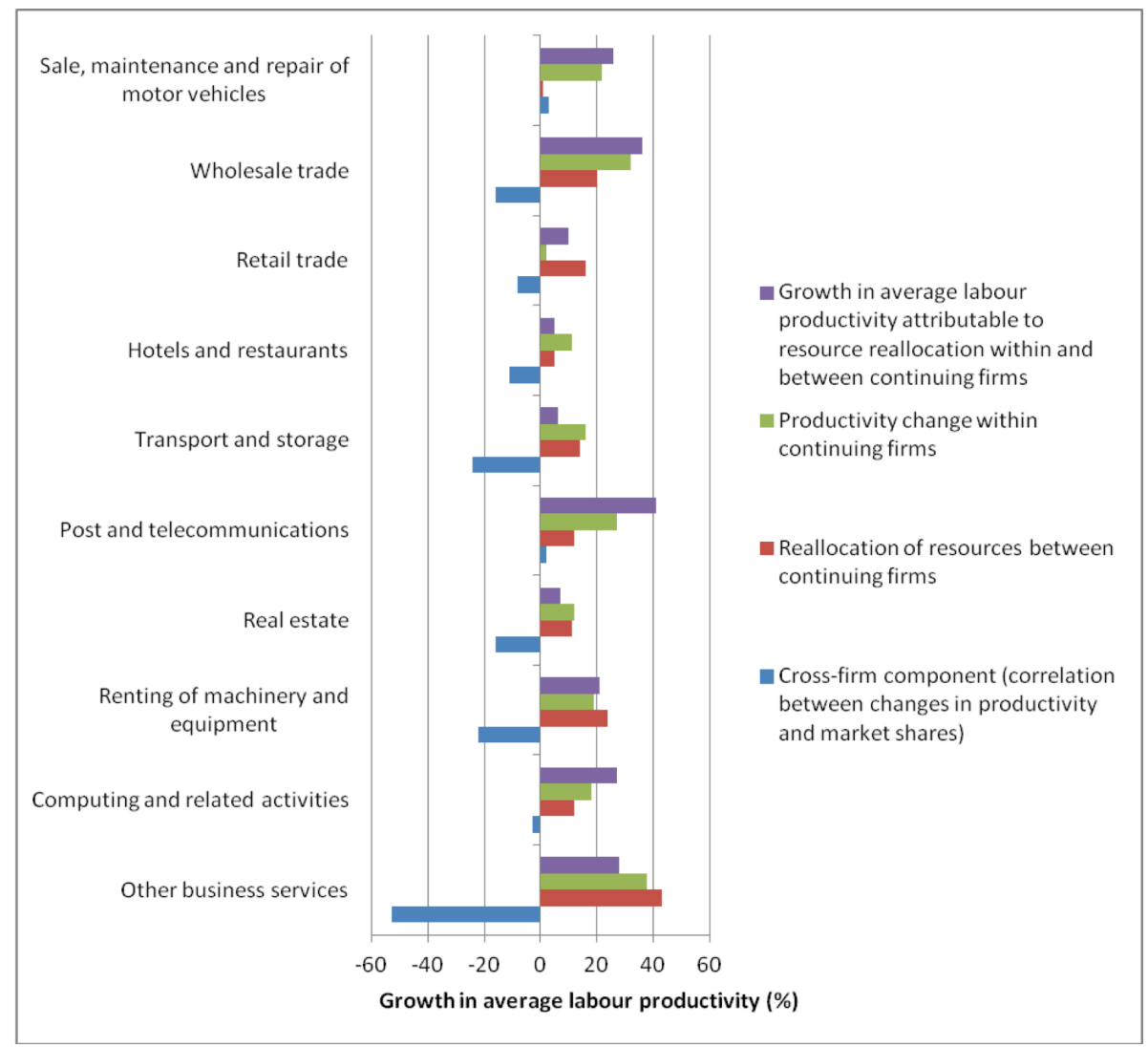

Source: ARD, authors' calculations. Detailed estimates are shown in Appendix Table B9.

This is particularly the case in real estate, computing and other business services, construction and food and drink manufacturing where the contributions to productivity growth from low-productivity exitors ranged from 11-17 pp (see Figures $8 \mathrm{~A}$ and $8 \mathrm{~B}$ ). But in a range of other service and manufacturing sectors - such as post and telecommunications, hotels and catering, retail, wood products, chemicals and transport equipment - the exit of low-productivity firms appears to be happening too slowly or on an insufficient scale for this form of restructuring to contribute substantially to productivity growth.

Many sectors recorded sizeable exit rates for firms with above-average productivity levels which partly or wholly offset the effects of weaker firms departing. 
Prominent examples included: i) mining/utilities where exitors with relatively high productivity levels depressed average labour productivity by -15 pp over the period, more than cancelling out the 6 pp contribution of low-productivity exitors; ii) other business services, $-8 \mathrm{pp}$ contribution from high-productivity exitors, partly offsetting the relatively high $17 \mathrm{pp}$ contribution from low-productivity exitors; iii) electrical and optical equipment manufacturing, $-7 \mathrm{pp}$ contribution from high-productivity exitors, more than offsetting the 5 pp contribution from low-productivity exitors; iv) non-metallic minerals manufacturing, $-7 \mathrm{pp}$ contribution from high-productivity exitors, more than offsetting the $5 \mathrm{pp}$ contribution from low-productivity exitors; v) other sectors with above-average reductions in productivity due to high-productivity exitors are construction, wholesale trade, renting of machinery and equipment and computer services.

Figure 8A. Decomposition of Labour Productivity Growth, 1998-2007, Analyzed by Sector, MP Decomposition with Entry and Exit above and below Average Labour Productivity: Manufacturing and other Production Sectors.

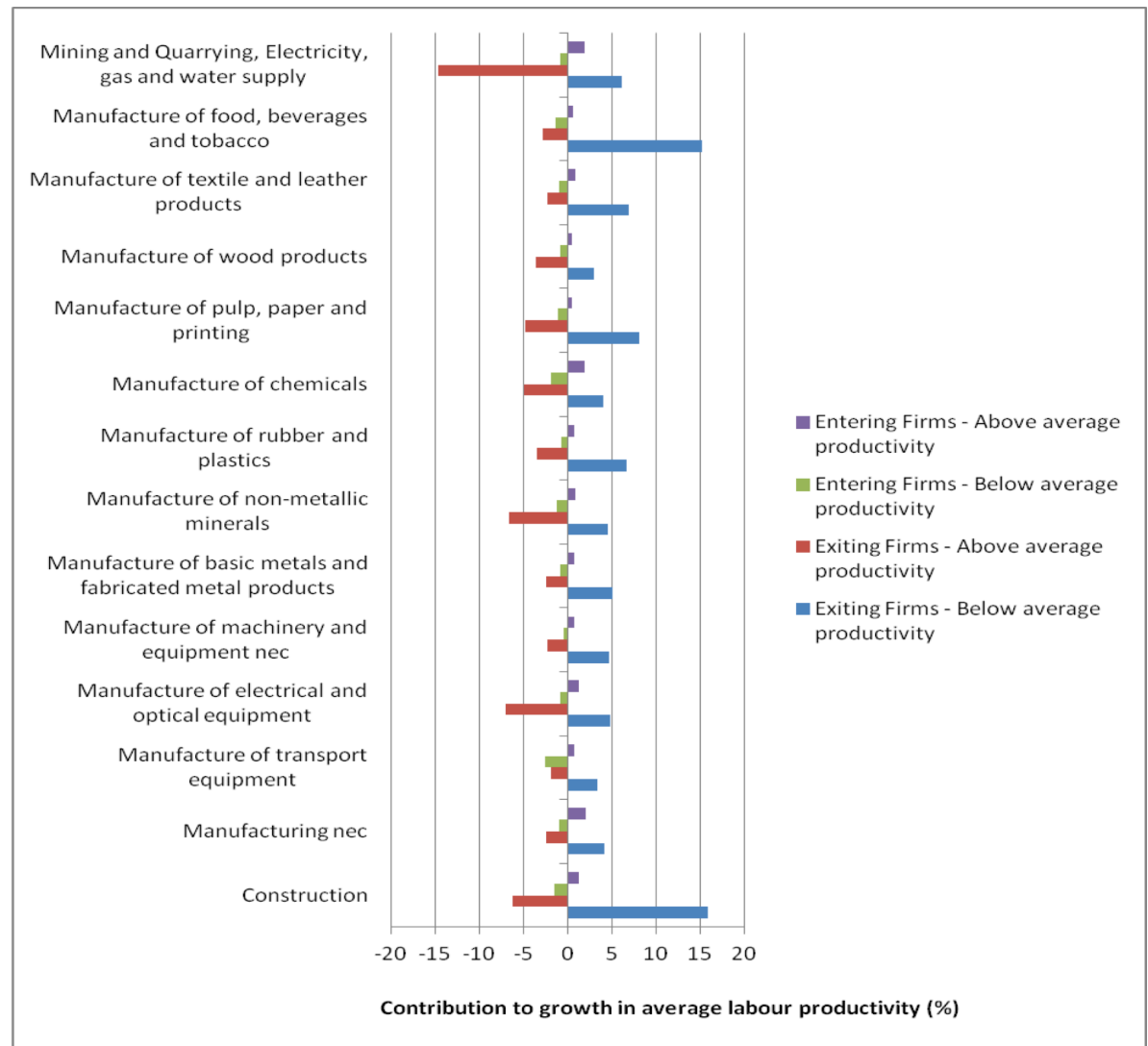

Source: ARD, authors' calculations. Detailed estimates are shown in Appendix Table B9.

Further research should be able to shed light on the main reasons for some high-productivity firms failing to survive in these and other sectors, 
for example, market imperfections such as funding constraints or anti-competitive practices.

Figure 8B. Decomposition of Labour Productivity Growth, 1998-2007, Analyzed by Sector, MP Decomposition with Entry and Exit above and below Average Labour Productivity: Service Sectors.

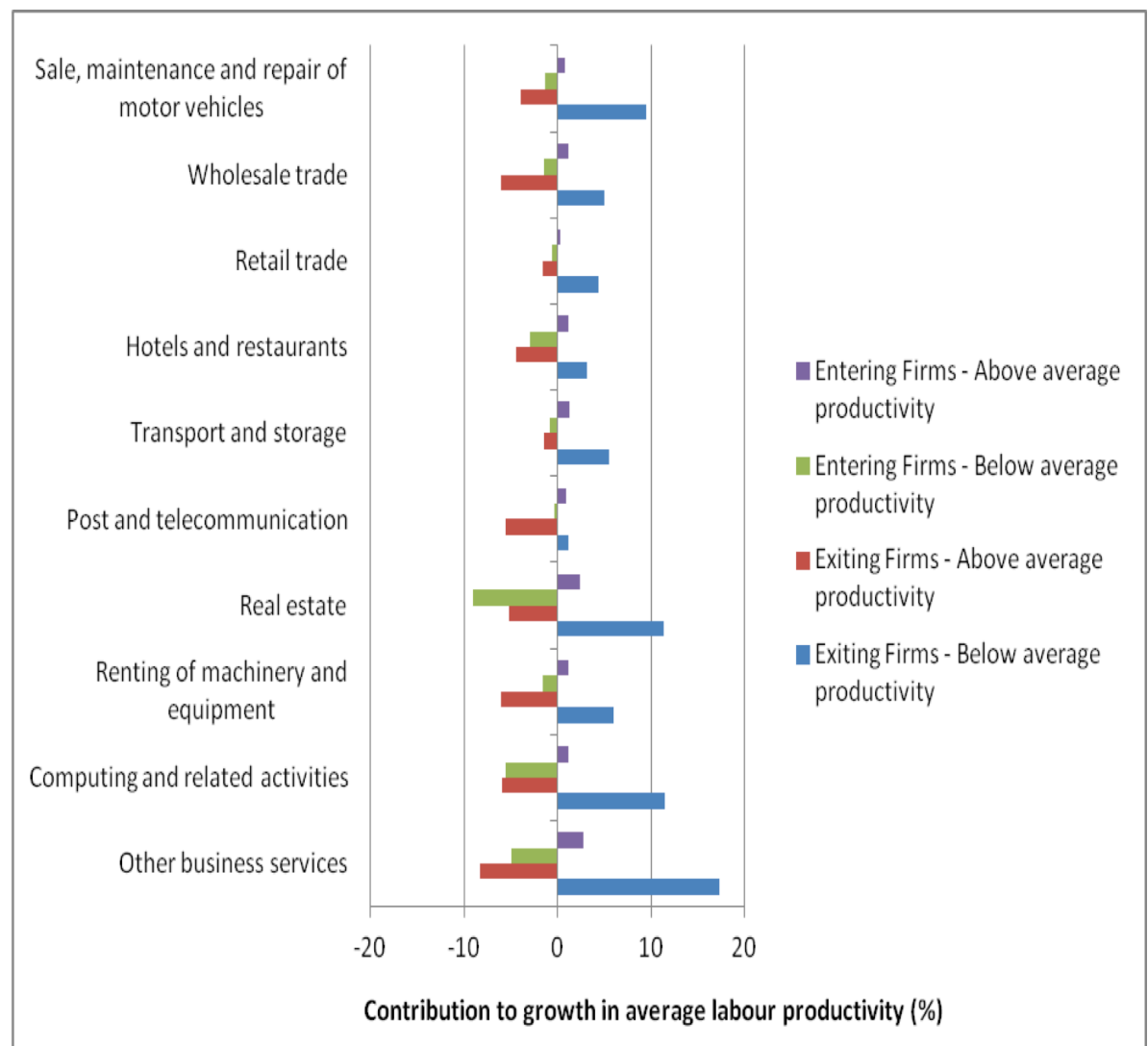

Source: ARD, authors' calculations. Detailed estimates are shown in Appendix Table B9.

\section{Summary and Assessment}

Our prime objective in this research has been to improve our understanding of allocative efficiency and the dynamics of labour productivity among firms using British data for the pre-recession period 1998-2007 and a range of decomposition methods. Compared to earlier work on Britain or the UK, we provide a more disaggregated sectoral breakdown and explicitly extend the analysis to include service sectors. In addition, we apply a series of approaches to consider the relationship between firm dynamics and performance at a detailed sector level for the first time in the British literature.

There are a number of components to our analysis. The first analytical strand considers the static decomposition of labour productivity levels using a detailed level of sectoral disaggregation. Our results show that 
allocative efficiency declined among firms with ten or more employees between 1998-2007, with the bulk of the decline occurring in service sectors such as retail and hotels and catering account for a large majority share of employment in the economy. However, by their nature, static decompositions are unable to disentangle entry and exit components of sectoral change from incumbent firm changes.

We therefore move to dynamic decompositions to look at sources of productivity growth at a disaggregated sectoral level in more detail. In view of the different strengths of the Foster, Haltiwanger and Krizan (FHK) and Melitz and Polanec (MP) decompositions described in Section 3 , we present two sets of disaggregated sector-level estimates, one using the FHK decomposition to examine resource reallocation within and between continuing firms; and the other using the MP decomposition to explore how new entrants and exiting firms divide between above-average and below-average productivity performers.

During this period internal restructuring within continuing firms contributed an estimated 20 percentage points (pp) to growth in average labour productivity in the total economy (including firms with 1-9 employees). But average labour productivity in the total economy grew by only $16 \%$ over this period as the effects of internal restructuring within continuing firms were partly offset by negative growth of $-4 \mathrm{pp}$ in the combined effects of external restructuring (such as the reallocation of resources between continuing firms as some of them gained market share and others lost it, and the reallocation of resources arising from firms entering and exiting particular markets).

The main sectors where external restructuring had negative effects on productivity were hotels and restaurants, transport and storage, real estate and other business services, mining and utilities, food and drink manufacturing and textiles manufacturing.

The net effects of firm entry and exit on productivity were found to be relatively small for the aggregate economy between 1998-2007. However, when entrants and exitors were disaggregated between firms with above-average productivity and those with below-average productivity, the overall negative effect of net entry was found to conceal a positive contribution of $1.5 \mathrm{pp}$ by high-productivity entrants which was more than cancelled out by the $-2.3 \mathrm{pp}$ contribution of low-productivity new firms. At the same time the relatively small positive net effect of firms exiting their markets concealed a 7.7 pp contribution by low-productivity exitors that was heavily offset by the -5.9 pp impact of firms exiting even though they had above-average productivity levels.

Low-productivity entrants were most conspicuous in business service sectors and in transport equipment manufacturing. This may reflect above-average ease of entry for weaker performers in those sectors. Further research would be useful to explore the extent to which such entrants survive and manage to improve their performance over time.

The exit of low-productivity firms made an important contribution to productivity growth in business services, construction and food and drink manufacturing but not in most other service or manufacturing sectors. In 
sectors such as post and telecommunications, hotels and catering, retail, wood products, chemicals and transport equipment, the exit of low-productivity firms appears to have happened too slowly or on an insufficient scale for this form of restructuring to contribute substantially to productivity growth.

Furthermore, in several sectors the exit of low-productivity firms was offset to a great extent by the exits of high-productivity firms. Examples of sectors in this category included mining/utilities, other business services, electrical and optical equipment manufacturing, non-metallic minerals manufacturing, construction, wholesale trade, renting of machinery and equipment and computer services.

This finding should be of particular interest to policy-makers since it shows that some enterprises with above-average productivity levels are failing to survive. Further research should aim to shed light on the main reasons for some high-productivity firms failing to survive in many sectors. Possible explanations include market imperfections such as funding constraints or anti-competitive practices.

As a final word of caution, our findings relate to changes in average labour productivity (ALP) and these represent only a partial measure of performance. Total factor productivity (TFP) is a useful measure of the efficiency of resource utilization and indeed it may be that firms experiencing high ALP growth do not necessarily experience high TFP growth, particularly if the ALP growth is due primarily to the substitution of capital for labour inputs. Further development of enterprise-level capital stocks estimates would allow the ARD analysis to be extended to explore TFP effects.

\section{References}

Disney, R., Haskel, J., Heden, Y., 2003. Restructuring and Productivity Growth in UK Manufacturing. The Economic Journal 113, 666-694.

Foster, L., Haltiwanger, J., Krizan, C. (2001), Aggregate Productivity Growth: Lessons from Microeconomic Evidence. In Hulten, C., Dean, E., Harper, M. (Eds.), New Developments in Productivity Analysis, University of Chicago Press, Chicago, pp. 303-372.

Harris, R., Moffat, J., 2012. Total Factor Productivity Growth in Local Economic Partnership Regions in Britain, 1997-2008. SERC Discussion Paper 112, London: Spatial Economics Research Centre.

Harris, R., Robinson, C., 2005. Impact of Regional Selective Assistance on Sources of Productivity Growth: Plant Level Evidence from UK Manufacturing. Regional Studies 39, 751-765.

Mason, G., Robinson, C., Rosazza Bondibene, C., 2014. Sources of Labour Productivity Growth at Sector Level in Britain, 1998-2007: A Firm-level 
Analysis. NESTA Working Paper 14/09, London: National Endowment for Science, Technology and the Arts.

Office for National Statistics, Annual Respondents Database, 1973-2008: Secure Data Service Access [computer file]. Colchester, Essex: UK Data Archive [distributor], March 2011. SN: 6644, http: / / dx.doi.org/10.5255/UKDA-SN-6644-1

Office for National Statistics, Business Structure Database, 1997-2010: Secure Data Service Access [computer file]. 2nd Edition. Colchester, Essex: UK Data Archive [distributor], November 2011. SN: 6697, http: / / dx.doi.org/10.5255/UKDA-SN-6697-1.

Olley, S., Pakes, A., 1996. The Dynamics of Productivity in the Telecommunications Equipment Industry. Econometrica 64, 1263-1298.

Oulton, N. (2000), A tale of two cities: closure, downsizing, and productivity growth in UK manufacturing, 1973-89, National Institute Economic Review, 173, 66-79.

Melitz, M., Polanec, S., 2015. Dynamic Olley-Pakes Productivity Decomposition with Entry and Exit. Rand Journal of Economics 46, 362-375.

Riley, R., Rosazza Bondibene, C., 2016. Sources of Labour Productivity Growth at Sector Level in Britain, After 2007: A Firm-level Analysis. NESTA Working Paper 16/01, London: National Endowment for Science, Technology and the Arts. 


\section{Appendix A: Static decompositions 1998-2007, detailed sector-level estimates}

Table A1. Static Olley-Pakes Decompositions 1998-2007 for Manufacturing Sectors (bottom-up aggregation), Firms with 10 or more Employees

\begin{tabular}{|c|c|c|c|c|}
\hline Sectors & $\begin{array}{c}\text { Average } \\
\text { Productivity } \\
\text { (weighted) }\end{array}$ & $\begin{array}{c}\text { Average } \\
\text { Productivity } \\
\text { (unweighted) }\end{array}$ & $\begin{array}{l}\text { Allocative } \\
\text { Efficiency }\end{array}$ & $\mathrm{N}[\#]$ \\
\hline \multicolumn{5}{|l|}{$1998-2000$} \\
\hline Total Economy & 3.215 & 2.978 & 0.237 & 78,027 \\
\hline Manufacturing & 3.574 & 3.388 & 0.186 & 28,533 \\
\hline Manufacture of food, beverages and tobacco (DA) & 3.474 & 3.2 & 0.274 & 2,799 \\
\hline Manufacture of textiles and textile products (DB) & 2.791 & 2.706 & 0.085 & 2,157 \\
\hline Manufacture of leather products (DC) & 2.878 & 2.7 & 0.179 & 252 \\
\hline Manufacture of wood products (DD) & 3.234 & 3.18 & 0.054 & 720 \\
\hline Manufacture of pulp, paper and printing (DE) & 3.663 & 3.53 & 0.133 & 3,530 \\
\hline Manufacture of coke, refined petroleum products and nuclear fuel (DF) & 4.339 & 4.225 & 0.114 & 93 \\
\hline Manufacture of chemicals (DG) & 4.016 & 3.767 & 0.248 & 1,811 \\
\hline Manufacture of rubber and plastics (DH) & 3.407 & 3.273 & 0.134 & 1,847 \\
\hline Manufacture of non-metallic minerals (DI) & 3.392 & 3.298 & 0.094 & 1,219 \\
\hline Manufacture of basic metals and fabricated metal products (DJ) & 3.348 & 3.258 & 0.089 & 4,493 \\
\hline Manufacture of machinery and equipment NEC (DK) & 3.302 & 3.281 & 0.021 & 2,989 \\
\hline Manufacture of electrical and optical equipment (DL) & 3.351 & 3.171 & 0.18 & 3,325 \\
\hline Manufacture of transport equipment (DM) & 3.626 & 3.388 & 0.237 & 1,589 \\
\hline Manufacturing NEC (DN) & 3.232 & 3.159 & 0.073 & 1,709 \\
\hline \multicolumn{5}{|l|}{$2001-2003$} \\
\hline Total Economy & 3.214 & 3.028 & 0.186 & 82,299 \\
\hline Manufacturing & 3.527 & 3.388 & 0.139 & 27,664 \\
\hline Manufacture of food, beverages and tobacco (DA) & 3.547 & 3.293 & 0.253 & 2,734 \\
\hline Manufacture of textiles and textile products (DB) & 2.938 & 2.859 & 0.079 & 1,865 \\
\hline Manufacture of leather products (DC) & 2.89 & 2.872 & 0.018 & 205 \\
\hline Manufacture of wood products (DD) & 3.349 & 3.286 & 0.063 & 705 \\
\hline Manufacture of pulp, paper and printing (DE) & 3.748 & 3.57 & 0.178 & 3,357 \\
\hline Manufacture of coke, refined petroleum products and nuclear fuel (DF) & 3.363 & 4.083 & -0.719 & 76 \\
\hline Manufacture of chemicals (DG) & 4.101 & 3.808 & 0.293 & 1,681 \\
\hline Manufacture of rubber and plastics (DH) & 3.408 & 3.296 & 0.113 & 1,792 \\
\hline Manufacture of non-metallic minerals (DI) & 3.576 & 3.344 & 0.232 & 1,166 \\
\hline Manufacture of basic metals and fabricated metal products (DJ) & 3.421 & 3.346 & 0.076 & 4,533 \\
\hline Manufacture of machinery and equipment NEC (DK) & 3.431 & 3.353 & 0.078 & 2,894 \\
\hline Manufacture of electrical and optical equipment (DL) & 3.383 & 3.285 & 0.098 & 3,191 \\
\hline Manufacture of transport equipment (DM) & 3.516 & 3.408 & 0.108 & 1,618 \\
\hline Manufacturing NEC (DN) & 3.252 & 3.227 & 0.026 & 1,847 \\
\hline \multicolumn{5}{|l|}{$2004-2007$} \\
\hline Total Economy & 3.314 & 3.153 & 0.161 & 94,345 \\
\hline Manufacturing & 3.682 & 3.512 & 0.17 & 31,341 \\
\hline Manufacture of food, beverages and tobacco (DA) & 3.596 & 3.367 & 0.229 & 3,090 \\
\hline Manufacture of textiles and textile products (DB) & 3.189 & 3.082 & 0.106 & 2,036 \\
\hline Manufacture of leather products (DC) & 3.174 & 3.145 & 0.029 & 218 \\
\hline Manufacture of wood products (DD) & 3.435 & 3.391 & 0.044 & 894 \\
\hline Manufacture of pulp, paper and printing (DE) & 3.759 & 3.633 & 0.126 & 3,654 \\
\hline Manufacture of coke, refined petroleum products and nuclear fuel (DF) & 5.117 & 4.38 & 0.737 & 90 \\
\hline Manufacture of chemicals (DG) & 4.064 & 3.808 & 0.255 & 1,936 \\
\hline Manufacture of rubber and plastics (DH) & 3.487 & 3.405 & 0.083 & 2,063 \\
\hline Manufacture of non-metallic minerals (DI) & 3.734 & 3.423 & 0.311 & 1,289 \\
\hline Manufacture of basic metals and fabricated metal products (DJ) & 3.59 & 3.5 & 0.09 & 5,082 \\
\hline Manufacture of machinery and equipment NEC (DK) & 3.646 & 3.555 & 0.091 & 3,329 \\
\hline Manufacture of electrical and optical equipment (DL) & 3.655 & 3.509 & 0.146 & 3,631 \\
\hline Manufacture of transport equipment (DM) & 3.793 & 3.569 & 0.223 & 1,905 \\
\hline Manufacturing NEC (DN) & 3.408 & 3.321 & 0.087 & 2,124 \\
\hline
\end{tabular}

Source: ARD, authors' calculations (firms with 10 or more employees; employment weights; bottom-up aggregation). 
Table A2. Static Olley-Pakes Decompositions 1998-2007 for Service Sectors (bottom-up aggregation), Firms with 10 or more Employees

\begin{tabular}{|c|c|c|c|c|}
\hline Sectors & $\begin{array}{c}\text { Average } \\
\text { Productivity } \\
\text { (weighted) }\end{array}$ & $\begin{array}{c}\text { Average } \\
\text { Productivity } \\
\text { (unweighted) }\end{array}$ & $\begin{array}{l}\text { Allocative } \\
\text { Efficiency }\end{array}$ & $\mathrm{N}[\#]$ \\
\hline \multicolumn{5}{|l|}{ 1998-2000 } \\
\hline Total Economy & 3.215 & 2.978 & 0.237 & 78,027 \\
\hline Services & 3.026 & 2.744 & 0.282 & 43,691 \\
\hline sale maintenance and repair of motor vehicles, retail sale of fuel & 3.229 & 3.08 & 0.149 & 3,904 \\
\hline wholesale and commission trade except motor vehicles & 3.343 & 3.3 & 0.043 & 10,187 \\
\hline retail trade except of motor vehicles & 2.759 & 2.229 & 0.53 & 6,696 \\
\hline hotels and restaurants & 2.675 & 2.176 & 0.499 & 4,352 \\
\hline land transport & 3.384 & 3.245 & 0.138 & 1,930 \\
\hline water transport & 3.854 & 3.577 & 0.277 & 173 \\
\hline air transport & 4.158 & 3.978 & 0.181 & 168 \\
\hline other supporting transport activities & 3.545 & 3.447 & 0.098 & 1,777 \\
\hline post and telecommunications & 3.799 & 3.398 & 0.401 & 405 \\
\hline real estate & 3.442 & 3.486 & -0.044 & 1,402 \\
\hline renting of machinery and equipment & 3.719 & 3.628 & 0.091 & 820 \\
\hline computing and related activities & 4.068 & 3.728 & 0.341 & 1,387 \\
\hline$R \& D$ & 3.439 & 3.384 & 0.056 & 298 \\
\hline other business services & 2.754 & 2.734 & 0.02 & 10,192 \\
\hline \multicolumn{5}{|l|}{$2001-2003$} \\
\hline Total Economy & 3.214 & 3.028 & 0.186 & 82,299 \\
\hline Services & 3.055 & 2.856 & 0.2 & 48,109 \\
\hline sale maintenance and repair of motor vehicles, retail sale of fuel & 3.315 & 3.227 & 0.088 & 4,089 \\
\hline wholesale and commission trade except motor vehicles & 3.35 & 3.368 & -0.017 & 10,526 \\
\hline retail trade except of motor vehicles & 2.748 & 2.413 & 0.335 & 7,251 \\
\hline hotels and restaurants & 2.65 & 2.285 & 0.365 & 5,182 \\
\hline land transport & 3.328 & 3.342 & -0.014 & 2,263 \\
\hline water transport & 4.099 & 3.862 & 0.237 & 183 \\
\hline air transport & 4.088 & 4.111 & -0.024 & 148 \\
\hline other supporting transport activities & 3.51 & 3.486 & 0.024 & 1,998 \\
\hline post and telecommunications & 3.743 & 3.319 & 0.424 & 594 \\
\hline real estate & 3.434 & 3.444 & -0.01 & 1,627 \\
\hline renting of machinery and equipment & 3.829 & 3.719 & 0.111 & 944 \\
\hline computing and related activities & 4.026 & 3.733 & 0.293 & 1,619 \\
\hline$R \& D$ & 3.522 & 3.46 & 0.062 & 304 \\
\hline other business services & 2.888 & 2.836 & 0.052 & 11,381 \\
\hline \multicolumn{5}{|l|}{$2004-2007$} \\
\hline Total Economy & 3.314 & 3.153 & 0.161 & 94,345 \\
\hline Services & 3.167 & 3.001 & 0.167 & 56,005 \\
\hline sale maintenance and repair of motor vehicles, retail sale of fuel & 3.485 & 3.325 & 0.16 & 4,317 \\
\hline wholesale and commission trade except motor vehicles & 3.542 & 3.576 & -0.035 & 13,234 \\
\hline retail trade except of motor vehicles & 2.806 & 2.573 & 0.233 & 8,333 \\
\hline hotels and restaurants & 2.73 & 2.371 & 0.359 & 5,068 \\
\hline land transport & 3.347 & 3.424 & -0.076 & 2,338 \\
\hline water transport & 4.249 & 3.978 & 0.271 & 243 \\
\hline air transport & 4.275 & 4.256 & 0.018 & 172 \\
\hline other supporting transport activities & 3.795 & 3.627 & 0.168 & 2,416 \\
\hline post and telecommunications & 3.825 & 3.51 & 0.316 & 733 \\
\hline real estate & 3.455 & 3.488 & -0.034 & 2,130 \\
\hline renting of machinery and equipment & 3.796 & 3.809 & -0.013 & 1,128 \\
\hline computing and related activities & 4.204 & 3.919 & 0.285 & 2,135 \\
\hline$R \& D$ & 4.031 & 3.63 & 0.401 & 438 \\
\hline other business services & 3.035 & 2.973 & 0.062 & 13,320 \\
\hline
\end{tabular}

Source: ARD, authors' calculations (firms with 10 or more employees; employment weights; bottom-up aggregation). 
Table A3. Static Olley-Pakes Decompositions 1998-2007 for other Production Sectors (bottom-up aggregation), Firms with 10 or more Employees

\begin{tabular}{lcccc}
\hline \multicolumn{1}{c}{ Sectors } & $\begin{array}{c}\text { Average } \\
\text { Productivity } \\
\text { (weighted) }\end{array}$ & $\begin{array}{c}\text { Average } \\
\text { Productivity } \\
\text { (unweighted) }\end{array}$ & $\begin{array}{c}\text { Allocative } \\
\text { Efficiency }\end{array}$ & N [\#] \\
\hline 1998-2000 & & & & \\
\hline Total Economy & 3.215 & 2.978 & 0.237 & 78,027 \\
Other Production & 3.968 & 3.918 & 0.05 & 5,803 \\
Mining and Quarrying & 4.631 & 4.332 & 0.299 & 1,462 \\
Electricity, gas and Water supply & 4.899 & 4.973 & -0.074 & 307 \\
Construction & 3.565 & 3.431 & 0.134 & 42,431 \\
\hline 2001-2003 & & & & \\
\hline Total Economy & 3.214 & 3.028 & 0.186 & 82,299 \\
Other Production & 3.952 & 3.739 & 0.212 & 6,526 \\
Mining and Quarrying & 4.696 & 4.403 & 0.293 & 1,330 \\
Electricity, gas and Water supply & 5.008 & 4.67 & 0.338 & 370 \\
Construction & 3.656 & 3.478 & 0.178 & 51,329 \\
\hline 2004-2007 & & & & \\
\hline Total Economy & 3.314 & 3.153 & 0.161 & 94,345 \\
Other Production & 4.001 & 3.951 & 0.05 & 6,999 \\
Mining and Quarrying & 4.582 & 4.444 & 0.138 & 1,536 \\
Electricity, gas and Water supply & 4.773 & 4.952 & -0.179 & 435 \\
Construction & 3.704 & 3.603 & 0.1 & 70,802 \\
\hline
\end{tabular}

Source: ARD, authors' calculations (firms with 10 or more employees; employment weights; bottom-up aggregation). 
Table A4. Static Olley-Pakes Decompositions 1998-2007 for Manufacturing Sectors (top-down aggregation), Firms with 10 or more Employees

\begin{tabular}{|c|c|c|c|c|}
\hline Sectors & $\begin{array}{c}\text { Average } \\
\text { Productivity } \\
\text { (weighted) }\end{array}$ & $\begin{array}{c}\text { Average } \\
\text { Productivity } \\
\text { (unweighted) }\end{array}$ & $\begin{array}{l}\text { Allocative } \\
\text { Efficiency }\end{array}$ & $\mathrm{N}[\#]$ \\
\hline \multicolumn{5}{|l|}{$1998-2000$} \\
\hline Total Economy & 3.215 & 3.149 & 0.066 & 78,027 \\
\hline Manufacturing & 3.466 & 3.266 & 0.2 & 28,533 \\
\hline Manufacture of food, beverages and tobacco (DA) & 3.474 & 3.22 & 0.255 & 2,799 \\
\hline Manufacture of textiles and textile products (DB) & 2.794 & 2.736 & 0.058 & 2,157 \\
\hline Manufacture of leather products (DC) & 2.874 & 2.695 & 0.179 & 252 \\
\hline Manufacture of wood products (DD) & 3.239 & 3.183 & 0.057 & 720 \\
\hline Manufacture of pulp, paper and printing (DE) & 3.663 & 3.483 & 0.18 & 3,530 \\
\hline Manufacture of coke, refined petroleum products and nuclear fuel (DF) & 4.297 & 4.201 & 0.095 & 93 \\
\hline Manufacture of chemicals (DG) & 4.016 & 3.785 & 0.231 & 1,811 \\
\hline Manufacture of rubber and plastics (DH) & 3.407 & 3.281 & 0.126 & 1,847 \\
\hline Manufacture of non-metallic minerals (DI) & 3.398 & 3.32 & 0.078 & 1,219 \\
\hline Manufacture of basic metals and fabricated metal products (DJ) & 3.348 & 3.244 & 0.103 & 4,493 \\
\hline Manufacture of machinery and equipment NEC (DK) & 3.302 & 3.287 & 0.015 & 2,989 \\
\hline Manufacture of electrical and optical equipment (DL) & 3.353 & 3.162 & 0.19 & 3,325 \\
\hline Manufacture of transport equipment (DM) & 3.629 & 3.39 & 0.239 & 1,589 \\
\hline Manufacturing NEC (DN) & 3.231 & 3.138 & 0.094 & 1,709 \\
\hline \multicolumn{5}{|l|}{$2001-2003$} \\
\hline Total Economy & 3.214 & 3.221 & -0.007 & 82,299 \\
\hline Manufacturing & 3.529 & 3.343 & 0.186 & 27,664 \\
\hline Manufacture of food, beverages and tobacco (DA) & 3.549 & 3.313 & 0.236 & 2,734 \\
\hline Manufacture of textiles and textile products (DB) & 2.95 & 2.863 & 0.087 & 1,865 \\
\hline Manufacture of leather products (DC) & 2.916 & 2.884 & 0.033 & 205 \\
\hline Manufacture of wood products (DD) & 3.348 & 3.285 & 0.063 & 705 \\
\hline Manufacture of pulp, paper and printing (DE) & 3.751 & 3.517 & 0.233 & 3,357 \\
\hline Manufacture of coke, refined petroleum products and nuclear fuel (DF) & 3.349 & 4.08 & -0.731 & 76 \\
\hline Manufacture of chemicals (DG) & 4.099 & 3.842 & 0.257 & 1,681 \\
\hline Manufacture of rubber and plastics (DH) & 3.408 & 3.3 & 0.108 & 1,792 \\
\hline Manufacture of non-metallic minerals (DI) & 3.579 & 3.352 & 0.227 & 1,166 \\
\hline Manufacture of basic metals and fabricated metal products (DJ) & 3.424 & 3.334 & 0.09 & 4,533 \\
\hline Manufacture of machinery and equipment NEC (DK) & 3.434 & 3.355 & 0.079 & 2,894 \\
\hline Manufacture of electrical and optical equipment (DL) & 3.386 & 3.285 & 0.101 & 3,191 \\
\hline Manufacture of transport equipment (DM) & 3.516 & 3.397 & 0.119 & 1,618 \\
\hline Manufacturing NEC (DN) & 3.254 & 3.235 & 0.019 & 1,847 \\
\hline \multicolumn{5}{|l|}{ 2004-2007 } \\
\hline Total Economy & 3.316 & 3.368 & -0.053 & 94,345 \\
\hline Manufacturing & 3.682 & 3.471 & 0.211 & 31,341 \\
\hline Manufacture of food, beverages and tobacco (DA) & 3.594 & 3.383 & 0.212 & 3,090 \\
\hline Manufacture of textiles and textile products (DB) & 3.19 & 3.074 & 0.116 & 2,036 \\
\hline Manufacture of leather products (DC) & 3.185 & 3.148 & 0.037 & 218 \\
\hline Manufacture of wood products (DD) & 3.436 & 3.393 & 0.043 & 894 \\
\hline Manufacture of pulp, paper and printing (DE) & 3.756 & 3.543 & 0.212 & 3,654 \\
\hline Manufacture of coke, refined petroleum products and nuclear fuel (DF) & 5.115 & 4.382 & 0.734 & 90 \\
\hline Manufacture of chemicals (DG) & 4.052 & 3.821 & 0.231 & 1,936 \\
\hline Manufacture of rubber and plastics (DH) & 3.49 & 3.406 & 0.084 & 2,063 \\
\hline Manufacture of non-metallic minerals (DI) & 3.731 & 3.436 & 0.295 & 1,289 \\
\hline Manufacture of basic metals and fabricated metal products (DJ) & 3.593 & 3.481 & 0.112 & 5,082 \\
\hline Manufacture of machinery and equipment NEC (DK) & 3.648 & 3.563 & 0.085 & 3,329 \\
\hline Manufacture of electrical and optical equipment (DL) & 3.657 & 3.512 & 0.145 & 3,631 \\
\hline Manufacture of transport equipment (DM) & 3.787 & 3.549 & 0.239 & 1,905 \\
\hline Manufacturing NEC (DN) & 3.408 & 3.336 & 0.073 & 2,124 \\
\hline
\end{tabular}

Source: ARD, authors' calculations (firms with 10 or more employees; employment weights; bottom-up aggregation). 
Table A5. Static Olley-Pakes Decompositions 1998-2007 for Service Sectors (top-down aggregation), Firms with 10 or more Employees

\begin{tabular}{|c|c|c|c|c|}
\hline Sectors & $\begin{array}{c}\text { Average } \\
\text { Productivity } \\
\text { (weighted) }\end{array}$ & $\begin{array}{c}\text { Average } \\
\text { Productivity } \\
\text { (unweighted) }\end{array}$ & $\begin{array}{l}\text { Allocative } \\
\text { Efficiency }\end{array}$ & $\mathrm{N}[\#]$ \\
\hline \multicolumn{5}{|l|}{ 1998-2000 } \\
\hline Total Economy & 3.215 & 3.149 & 0.066 & 78,027 \\
\hline Services & 3.026 & 3.015 & 0.01 & 43,691 \\
\hline sale maintenance and repair of motor vehicles, retail sale of fuel & 3.228 & 3.044 & 0.184 & 3,904 \\
\hline wholesale and commission trade except motor vehicles & 3.342 & 3.296 & 0.046 & 10,187 \\
\hline retail trade except of motor vehicles & 2.762 & 2.377 & 0.385 & 6,696 \\
\hline hotels and restaurants & 2.675 & 2.244 & 0.431 & 4,352 \\
\hline land transport & 3.383 & 3.216 & 0.167 & 1,930 \\
\hline water transport & 3.843 & 3.589 & 0.254 & 173 \\
\hline air transport & 4.162 & 3.974 & 0.187 & 168 \\
\hline other supporting transport activities & 3.553 & 3.447 & 0.105 & 1,777 \\
\hline post and telecommunications & 3.91 & 3.367 & 0.543 & 405 \\
\hline real estate & 3.445 & 3.547 & -0.101 & 1,402 \\
\hline renting of machinery and equipment & 3.726 & 3.659 & 0.068 & 820 \\
\hline computing and related activities & 4.068 & 3.784 & 0.284 & 1,387 \\
\hline$R \& D$ & 3.459 & 3.388 & 0.072 & 298 \\
\hline other business services & 2.752 & 3.079 & -0.327 & 10,192 \\
\hline \multicolumn{5}{|l|}{$2001-2003$} \\
\hline Total Economy & 3.214 & 3.221 & -0.007 & 82,299 \\
\hline Services & 3.056 & 3.1 & -0.044 & 48,109 \\
\hline sale maintenance and repair of motor vehicles, retail sale of fuel & 3.313 & 3.202 & 0.111 & 4,089 \\
\hline wholesale and commission trade except motor vehicles & 3.35 & 3.369 & -0.018 & 10,526 \\
\hline retail trade except of motor vehicles & 2.749 & 2.611 & 0.139 & 7,251 \\
\hline hotels and restaurants & 2.649 & 2.337 & 0.312 & 5,182 \\
\hline land transport & 3.331 & 3.284 & 0.047 & 2,263 \\
\hline water transport & 4.099 & 3.863 & 0.236 & 183 \\
\hline air transport & 4.097 & 4.106 & -0.009 & 148 \\
\hline other supporting transport activities & 3.513 & 3.474 & 0.039 & 1,998 \\
\hline post and telecommunications & 3.824 & 3.382 & 0.443 & 594 \\
\hline real estate & 3.437 & 3.503 & -0.066 & 1,627 \\
\hline renting of machinery and equipment & 3.829 & 3.729 & 0.1 & 944 \\
\hline computing and related activities & 4.023 & 3.752 & 0.271 & 1,619 \\
\hline$R \& D$ & 3.505 & 3.461 & 0.044 & 304 \\
\hline other business services & 2.888 & 3.118 & -0.23 & 11,381 \\
\hline \multicolumn{5}{|l|}{$2004-2007$} \\
\hline Total Economy & 3.316 & 3.368 & -0.053 & 94,345 \\
\hline Services & 3.169 & 3.268 & -0.099 & 56,005 \\
\hline sale maintenance and repair of motor vehicles, retail sale of fuel & 3.486 & 3.282 & 0.204 & 4,317 \\
\hline wholesale and commission trade except motor vehicles & 3.544 & 3.578 & -0.034 & 13,234 \\
\hline retail trade except of motor vehicles & 2.811 & 2.769 & 0.041 & 8,333 \\
\hline hotels and restaurants & 2.729 & 2.434 & 0.295 & 5,068 \\
\hline land transport & 3.348 & 3.337 & 0.011 & 2,338 \\
\hline water transport & 4.225 & 3.962 & 0.263 & 243 \\
\hline air transport & 4.276 & 4.261 & 0.014 & 172 \\
\hline other supporting transport activities & 3.791 & 3.612 & 0.179 & 2,416 \\
\hline post and telecommunications & 3.825 & 3.699 & 0.126 & 733 \\
\hline real estate & 3.45 & 3.573 & -0.123 & 2,130 \\
\hline renting of machinery and equipment & 3.795 & 3.823 & -0.027 & 1,128 \\
\hline computing and related activities & 4.203 & 3.942 & 0.261 & 2,135 \\
\hline$R \& D$ & 4.027 & 3.635 & 0.392 & 438 \\
\hline other business services & 3.038 & 3.239 & -0.201 & 13,320 \\
\hline
\end{tabular}

Source: ARD, authors' calculations (firms with 10 or more employees; employment weights; bottom-up aggregation). 
Table A6. Static Olley-Pakes Decompositions 1998-2007 for other Production Sectors (top-down aggregation), Firms with 10 or more Employees

\begin{tabular}{|c|c|c|c|c|}
\hline Sectors & $\begin{array}{c}\text { Average } \\
\text { Productivity } \\
\text { (weighted) }\end{array}$ & $\begin{array}{c}\text { Average } \\
\text { Productivity } \\
\text { (unweighted) }\end{array}$ & $\begin{array}{l}\text { Allocative } \\
\text { Efficiency }\end{array}$ & $\mathbf{N}[\#]$ \\
\hline \multicolumn{5}{|l|}{$1998-2000$} \\
\hline Total Economy & 3.215 & 3.149 & 0.066 & 78,027 \\
\hline Other Production & 4.023 & 3.586 & 0.437 & 5,803 \\
\hline Mining and Quarrying & 4.627 & 4.334 & 0.293 & 664 \\
\hline Electricity, gas and Water supply & 4.905 & 4.968 & -0.063 & 200 \\
\hline Construction & 3.564 & 3.429 & 0.134 & 4,939 \\
\hline \multicolumn{5}{|l|}{ 2001-2003 } \\
\hline Total Economy & 3.214 & 3.221 & -0.007 & 82,299 \\
\hline Other Production & 3.952 & 3.598 & 0.354 & 6,526 \\
\hline Mining and Quarrying & 4.694 & 4.403 & 0.291 & 640 \\
\hline Electricity, gas and Water supply & 5.006 & 4.658 & 0.348 & 189 \\
\hline Construction & 3.657 & 3.472 & 0.185 & 5,697 \\
\hline \multicolumn{5}{|l|}{ 2004-2007 } \\
\hline Total Economy & 3.316 & 3.368 & -0.053 & 94,345 \\
\hline Other Production & 4.000 & 3.713 & 0.286 & 6,999 \\
\hline Mining and Quarrying & 4.583 & 4.441 & 0.142 & 681 \\
\hline Electricity, gas and Water supply & 4.835 & 4.830 & 0.004 & 203 \\
\hline Construction & 3.705 & 3.593 & 0.112 & 6,115 \\
\hline
\end{tabular}

Source: ARD, authors' calculations (firms with 10 or more employees; employment weights; bottom-up aggregation). 


\section{Appendix B: Dynamic Decompositions, 1998-2007, Detailed Sector-level Estimates}

Table B1. Melitz-Polanec Decomposition 1998-2007, Employment Weighted

\begin{tabular}{|c|c|c|c|c|c|}
\hline \multirow{2}{*}{ Industry } & \multicolumn{2}{|c|}{ Surviving Firms } & \multirow{2}{*}{$\begin{array}{c}\text { Entering } \\
\text { Firms }\end{array}$} & \multirow{2}{*}{$\begin{array}{c}\text { Exiting } \\
\text { Firms }\end{array}$} & \multirow[b]{2}{*}{$\Delta \Pi_{I}$} \\
\hline & $\Delta \overline{\boldsymbol{\pi}}_{C}$ & $\Delta \operatorname{cov}_{C}$ & & & \\
\hline Mining and Quarrying, Electricity, gas and water supply & -0.02 & -0.08 & 0.01 & -0.09 & -0.18 \\
\hline Manufacture of food, beverages and tobacco & 0.01 & -0.16 & -0.01 & 0.12 & -0.03 \\
\hline Manufacture of textile and leather products & 0.20 & 0.22 & 0.00 & 0.05 & 0.46 \\
\hline Manufacture of wood products & -0.07 & 0.27 & -0.01 & -0.01 & 0.19 \\
\hline Manufacture of pulp, paper and printing & -0.04 & 0.13 & -0.01 & 0.03 & 0.12 \\
\hline Manufacture of chemicals & -0.07 & 0.15 & 0.00 & -0.01 & 0.07 \\
\hline Manufacture of rubber & 0.07 & 0.10 & 0.00 & 0.03 & 0.20 \\
\hline Manufacture of non-metallic minerals & -0.01 & 0.45 & 0.00 & -0.02 & 0.41 \\
\hline Manufacture of basic metals and fabricated metal products & 0.08 & 0.14 & 0.00 & 0.03 & 0.25 \\
\hline Manufacture of machinery and equipment NEC & 0.13 & 0.26 & 0.00 & 0.02 & 0.41 \\
\hline Manufacture of electrical and optical equipment & 0.27 & 0.24 & 0.00 & -0.02 & 0.49 \\
\hline Manufacture of transport equipment & 0.19 & 0.35 & -0.02 & 0.01 & 0.53 \\
\hline Manufacturing NEC & 0.03 & 0.14 & 0.01 & 0.02 & 0.19 \\
\hline Construction & -0.22 & 0.32 & 0.00 & 0.09 & 0.19 \\
\hline Sale, maintenance and repair of motor vehicles & 0.06 & 0.21 & -0.01 & 0.05 & 0.32 \\
\hline Wholesale trade & -0.02 & 0.40 & 0.00 & -0.01 & 0.36 \\
\hline Retail trade & -0.02 & 0.12 & 0.00 & 0.03 & 0.13 \\
\hline Hotels and restaurants & 0.11 & -0.05 & -0.02 & -0.01 & 0.02 \\
\hline Transport and storage & -0.01 & 0.07 & 0.00 & 0.04 & 0.11 \\
\hline Post and telecommunication & 0.19 & 0.22 & 0.01 & -0.04 & 0.38 \\
\hline Real estate & -0.12 & 0.20 & -0.07 & 0.06 & 0.08 \\
\hline Renting of machinery and equipment & 0.06 & 0.15 & 0.00 & 0.00 & 0.20 \\
\hline Computing and related activities & -0.13 & 0.42 & -0.04 & 0.06 & 0.30 \\
\hline$R \& D$ and other business services & 0.04 & 0.25 & -0.02 & 0.09 & 0.36 \\
\hline TOTAL ECONOMY & 0.01 & 0.14 & -0.01 & 0.02 & 0.16 \\
\hline
\end{tabular}

Table B2. Melitz-Polanec Decomposition 1998-2002, Employment Weighted

\begin{tabular}{|c|c|c|c|c|c|}
\hline \multirow{2}{*}{ Industry } & \multicolumn{2}{|c|}{ Surviving Firms } & \multirow{2}{*}{$\begin{array}{c}\text { Entering } \\
\text { Firms }\end{array}$} & \multirow{2}{*}{$\begin{array}{c}\text { Exiting } \\
\text { Firms }\end{array}$} & \multirow[b]{2}{*}{$\Delta \Pi_{I}$} \\
\hline & $\Delta \overline{\boldsymbol{\pi}}_{C}$ & $\Delta \operatorname{cov}_{C}$ & & & \\
\hline Mining and Quarrying, Electricity, gas and water supply & 0.16 & -0.18 & 0.00 & 0.00 & -0.02 \\
\hline Manufacture of food, beverages and tobacco & -0.06 & 0.12 & -0.01 & 0.03 & 0.08 \\
\hline Manufacture of textile and leather products & 0.04 & 0.07 & 0.00 & 0.02 & 0.12 \\
\hline Manufacture of wood products & -0.01 & 0.15 & 0.00 & -0.01 & 0.12 \\
\hline Manufacture of pulp, paper and printing & -0.06 & 0.06 & 0.00 & 0.01 & 0.01 \\
\hline Manufacture of chemicals & 0.00 & 0.04 & -0.01 & 0.01 & 0.03 \\
\hline Manufacture of rubber & -0.03 & 0.02 & 0.00 & 0.02 & 0.01 \\
\hline Manufacture of non-metallic minerals & -0.05 & 0.17 & 0.00 & 0.00 & 0.11 \\
\hline Manufacture of basic metals and fabricated metal products & 0.03 & 0.10 & 0.00 & 0.01 & 0.13 \\
\hline Manufacture of machinery and equipment NEC & -0.06 & -0.01 & 0.00 & 0.02 & -0.05 \\
\hline Manufacture of electrical and optical equipment & 0.10 & 0.03 & 0.00 & 0.01 & 0.14 \\
\hline Manufacture of transport equipment & -0.04 & -0.05 & 0.03 & -0.01 & -0.08 \\
\hline Manufacturing NEC & -0.02 & 0.00 & 0.00 & 0.00 & -0.02 \\
\hline Construction & -0.25 & 0.19 & -0.01 & 0.10 & 0.03 \\
\hline Sale, maintenance and repair of motor vehicles & -0.02 & 0.12 & 0.00 & -0.01 & 0.10 \\
\hline Wholesale trade & -0.12 & 0.23 & 0.00 & 0.00 & 0.10 \\
\hline Retail trade & -0.11 & 0.05 & 0.00 & 0.02 & -0.04 \\
\hline Hotels and restaurants & -0.03 & -0.05 & -0.01 & -0.02 & -0.11 \\
\hline Transport and storage & -0.03 & 0.01 & 0.00 & 0.01 & -0.01 \\
\hline Post and telecommunication & 0.06 & 0.09 & -0.03 & 0.02 & 0.14 \\
\hline Real estate & -0.14 & 0.08 & -0.15 & 0.06 & -0.15 \\
\hline Renting of machinery and equipment & 0.01 & 0.25 & 0.00 & -0.01 & 0.25 \\
\hline Computing and related activities & -0.14 & 0.26 & -0.01 & 0.00 & 0.11 \\
\hline$R \& D$ and other business services & -0.05 & 0.17 & 0.00 & 0.05 & 0.18 \\
\hline TOTAL ECONOMY & -0.07 & 0.07 & 0.00 & 0.02 & 0.01 \\
\hline
\end{tabular}


Table B3. Melitz-Polanec Decomposition 2003-2007, Employment Weighted

\begin{tabular}{lccccc}
\hline \multicolumn{1}{c}{ Industry } & \multicolumn{2}{c}{ Surviving Firms } & Entering & Exiting & \\
& $\Delta \overline{\boldsymbol{\pi}}_{\boldsymbol{C}}$ & $\Delta \boldsymbol{c o v}_{\boldsymbol{C}}$ & Firms & Firms & $\Delta \boldsymbol{\Pi}_{\boldsymbol{I}}$ \\
\hline Mining and Quarrying, Electricity, gas and water supply & -0.140 & -0.080 & 0.000 & 0.110 & $\mathbf{- 0 . 1 1 0}$ \\
Manufacture of food, beverages and tobacco & 0.040 & -0.020 & 0.000 & 0.000 & $\mathbf{0 . 0 3 0}$ \\
Manufacture of textile and leather products & 0.060 & 0.130 & 0.000 & 0.020 & $\mathbf{0 . 2 0 0}$ \\
Manufacture of wood products & -0.020 & 0.120 & 0.000 & 0.000 & $\mathbf{0 . 1 0 0}$ \\
Manufacture of pulp, paper and printing & -0.050 & 0.020 & 0.000 & -0.020 & $\mathbf{- 0 . 0 4 0}$ \\
Manufacture of chemicals & -0.110 & 0.150 & 0.000 & 0.020 & $\mathbf{0 . 0 6 0}$ \\
Manufacture of rubber & 0.060 & 0.080 & 0.000 & 0.010 & $\mathbf{0 . 1 5 0}$ \\
Manufacture of non-metallic minerals & 0.010 & 0.130 & 0.000 & -0.050 & $\mathbf{0 . 1 0 0}$ \\
Manufacture of basic metals and fabricated metal products & 0.030 & 0.140 & 0.000 & 0.000 & $\mathbf{0 . 1 8 0}$ \\
Manufacture of machinery and equipment NEC & 0.100 & 0.060 & 0.000 & 0.000 & $\mathbf{0 . 1 7 0}$ \\
Manufacture of electrical and optical equipment & 0.120 & 0.100 & 0.010 & 0.000 & $\mathbf{0 . 2 3 0}$ \\
Manufacture of transport equipment & 0.100 & 0.190 & 0.000 & 0.000 & $\mathbf{0 . 2 8 0}$ \\
Manufacturing NEC & -0.010 & 0.210 & 0.000 & 0.000 & $\mathbf{0 . 1 9 0}$ \\
Construction & -0.020 & 0.040 & 0.000 & 0.000 & $\mathbf{0 . 0 2 0}$ \\
Sale, maintenance and repair of motor vehicles & 0.040 & 0.040 & 0.000 & -0.010 & $\mathbf{0 . 0 7 0}$ \\
Wholesale trade & 0.120 & 0.050 & 0.000 & 0.010 & $\mathbf{0 . 1 9 0}$ \\
Retail trade & 0.000 & 0.130 & 0.000 & 0.010 & $\mathbf{0 . 1 5 0}$ \\
Hotels and restaurants & -0.070 & 0.210 & 0.000 & 0.000 & $\mathbf{0 . 1 4 0}$ \\
Transport and storage & 0.000 & 0.200 & 0.000 & 0.000 & $\mathbf{0 . 2 0 0}$ \\
Post and telecommunication & 0.120 & 0.210 & 0.000 & 0.020 & $\mathbf{0 . 3 6 0}$ \\
Real estate & -0.040 & 0.120 & 0.000 & 0.010 & $\mathbf{0 . 0 8 0}$ \\
Renting of machinery and equipment & 0.040 & 0.030 & 0.000 & -0.030 & $\mathbf{0 . 0 4 0}$ \\
Computing and related activities & 0.020 & 0.120 & -0.010 & 0.010 & $\mathbf{0 . 1 4 0}$ \\
R\&D and other business services & 0.050 & 0.110 & -0.010 & -0.010 & $\mathbf{0 . 1 4 0}$ \\
\hline TOTAL ECONOMY & 0.030 & 0.100 & 0.000 & 0.000 & $\mathbf{0 . 1 2 0}$ \\
\hline
\end{tabular}

Table B4. Melitz-Polanec Decomposition with Entry and Exit above and below Average Labour Productivity, 1998-2007

\begin{tabular}{|c|c|c|c|c|c|c|c|}
\hline \multirow{2}{*}{ Industry } & \multicolumn{2}{|c|}{ Surviving Firms } & \multicolumn{2}{|c|}{ Entering Firms } & \multicolumn{2}{|c|}{ Exiting Firms } & \multirow[b]{2}{*}{$\Delta \Pi_{I}$} \\
\hline & $\Delta \overline{\boldsymbol{\pi}}_{C}$ & $\Delta \operatorname{cov}_{C}$ & Above avg & Below avg & Above avg & Below avg & \\
\hline Mining and Quarrying, Electricity, gas and water supply & -0.020 & -0.080 & 0.019 & -0.008 & -0.147 & 0.061 & -0.180 \\
\hline Manufacture of food, beverages and tobacco & 0.010 & -0.160 & 0.006 & -0.014 & -0.028 & 0.152 & -0.030 \\
\hline Manufacture of textile and leather products & 0.200 & 0.220 & 0.008 & -0.010 & -0.023 & 0.069 & 0.460 \\
\hline Manufacture of wood products & -0.070 & 0.270 & 0.004 & -0.009 & -0.036 & 0.030 & 0.190 \\
\hline Manufacture of pulp, paper and printing & -0.040 & 0.130 & 0.005 & -0.011 & -0.048 & 0.081 & 0.120 \\
\hline Manufacture of chemicals & -0.070 & 0.150 & 0.019 & -0.019 & -0.049 & 0.040 & 0.070 \\
\hline Manufacture of rubber & 0.070 & 0.100 & 0.007 & -0.007 & -0.035 & 0.066 & 0.200 \\
\hline Manufacture of non-metallic minerals & -0.010 & 0.450 & 0.008 & -0.012 & -0.066 & 0.045 & 0.410 \\
\hline Manufacture of basic metals and fabricated metal products & 0.080 & 0.140 & 0.007 & -0.008 & -0.025 & 0.050 & 0.250 \\
\hline Manufacture of machinery and equipment NEC & 0.130 & 0.260 & 0.007 & -0.005 & -0.023 & 0.046 & 0.410 \\
\hline Manufacture of electrical and optical equipment & 0.270 & 0.240 & 0.012 & -0.009 & -0.070 & 0.048 & 0.490 \\
\hline Manufacture of transport equipment & 0.190 & 0.350 & 0.007 & -0.026 & -0.019 & 0.033 & 0.530 \\
\hline Manufacturing NEC & 0.030 & 0.140 & 0.020 & -0.010 & -0.024 & 0.041 & 0.190 \\
\hline Construction & -0.220 & 0.320 & 0.013 & -0.015 & -0.063 & 0.158 & 0.190 \\
\hline Sale, maintenance and repair of motor vehicles & 0.060 & 0.210 & 0.008 & -0.013 & -0.040 & 0.095 & 0.320 \\
\hline Wholesale trade & -0.020 & 0.400 & 0.011 & -0.015 & -0.060 & 0.050 & 0.360 \\
\hline Retail trade & -0.020 & 0.120 & 0.003 & -0.006 & -0.016 & 0.044 & 0.130 \\
\hline Hotels and restaurants & 0.110 & -0.050 & 0.012 & -0.030 & -0.045 & 0.031 & 0.020 \\
\hline Transport and storage & -0.010 & 0.070 & 0.013 & -0.009 & -0.015 & 0.055 & 0.110 \\
\hline Post and telecommunication & 0.190 & 0.220 & 0.009 & -0.004 & -0.055 & 0.011 & 0.380 \\
\hline Real estate & -0.120 & 0.200 & 0.024 & -0.090 & -0.052 & 0.113 & 0.080 \\
\hline Renting of machinery and equipment & 0.060 & 0.150 & 0.012 & -0.016 & -0.060 & 0.060 & 0.200 \\
\hline Computing and related activities & -0.130 & 0.420 & 0.011 & -0.055 & -0.059 & 0.114 & 0.300 \\
\hline$R \& D$ and other business services & 0.040 & 0.250 & 0.028 & -0.050 & -0.083 & 0.173 & 0.360 \\
\hline TOTAL ECONOMY & 0.010 & 0.140 & 0.015 & -0.023 & -0.059 & 0.077 & 0.160 \\
\hline
\end{tabular}


Table B5. Melitz-Polanec Decomposition with Entry and Exit above and below Average Labour Productivity, 1998-2002

\begin{tabular}{|c|c|c|c|c|c|c|c|}
\hline \multirow{2}{*}{ Industry } & \multicolumn{2}{|c|}{ Surviving Firms } & \multicolumn{2}{|c|}{ Entering Firms } & \multicolumn{2}{|c|}{ Exiting Firms } & \multirow[b]{2}{*}{$\Delta \Pi_{I}$} \\
\hline & $\Delta \overline{\boldsymbol{\pi}}_{C}$ & $\Delta \operatorname{cov}_{C}$ & Above avg & Below avg & Above avg & Below avg & \\
\hline Mining and Quarrying, Electricity, gas and water supply & 0.160 & -0.180 & 0.012 & -0.014 & -0.019 & 0.019 & -0.020 \\
\hline Manufacture of food, beverages and tobacco & -0.060 & 0.120 & 0.001 & -0.009 & -0.008 & 0.037 & 0.080 \\
\hline Manufacture of textile and leather products & 0.040 & 0.070 & 0.006 & -0.005 & -0.007 & 0.026 & 0.120 \\
\hline Manufacture of wood products & -0.010 & 0.150 & 0.001 & -0.005 & -0.018 & 0.008 & 0.120 \\
\hline Manufacture of pulp, paper and printing & -0.060 & 0.060 & 0.002 & -0.004 & -0.029 & 0.040 & 0.010 \\
\hline Manufacture of chemicals & 0.000 & 0.040 & 0.002 & -0.012 & -0.009 & 0.017 & 0.030 \\
\hline Manufacture of rubber & -0.030 & 0.020 & 0.005 & -0.005 & -0.018 & 0.036 & 0.010 \\
\hline Manufacture of non-metallic minerals & -0.050 & 0.170 & 0.002 & -0.005 & -0.016 & 0.013 & 0.110 \\
\hline Manufacture of basic metals and fabricated metal products & 0.030 & 0.100 & 0.003 & -0.007 & -0.013 & 0.022 & 0.130 \\
\hline Manufacture of machinery and equipment NEC & -0.060 & -0.010 & 0.002 & -0.004 & -0.006 & 0.023 & -0.050 \\
\hline Manufacture of electrical and optical equipment & 0.100 & 0.030 & 0.005 & -0.007 & -0.008 & 0.022 & 0.140 \\
\hline Manufacture of transport equipment & -0.040 & -0.050 & 0.030 & -0.003 & -0.029 & 0.017 & -0.080 \\
\hline Manufacturing NEC & -0.020 & 0.000 & 0.004 & -0.004 & -0.012 & 0.013 & -0.020 \\
\hline Construction & -0.250 & 0.190 & 0.006 & -0.016 & -0.015 & 0.110 & 0.030 \\
\hline Sale, maintenance and repair of motor vehicles & -0.020 & 0.120 & 0.005 & -0.007 & -0.023 & 0.018 & 0.100 \\
\hline Wholesale trade & -0.120 & 0.230 & 0.005 & -0.007 & -0.027 & 0.023 & 0.100 \\
\hline Retail trade & -0.110 & 0.050 & 0.001 & -0.002 & -0.005 & 0.020 & -0.040 \\
\hline Hotels and restaurants & -0.030 & -0.050 & 0.003 & -0.010 & -0.033 & 0.016 & -0.110 \\
\hline Transport and storage & -0.030 & 0.010 & 0.004 & -0.004 & -0.002 & 0.011 & -0.010 \\
\hline Post and telecommunication & -0.097 & 0.074 & 0.006 & -0.006 & -0.017 & 0.026 & 0.140 \\
\hline Real estate & -0.104 & 0.076 & 0.006 & -0.006 & -0.017 & 0.026 & -0.150 \\
\hline Renting of machinery and equipment & 0.010 & 0.250 & 0.004 & -0.007 & -0.029 & 0.016 & 0.250 \\
\hline Computing and related activities & -0.140 & 0.260 & 0.011 & -0.024 & -0.047 & 0.047 & 0.110 \\
\hline$R \& D$ and other business services & -0.050 & 0.170 & 0.027 & -0.025 & -0.029 & 0.083 & 0.180 \\
\hline TOTAL ECONOMY & -0.070 & 0.070 & 0.010 & -0.012 & -0.020 & 0.037 & 0.010 \\
\hline
\end{tabular}

Table B6. Melitz-Polanec Decomposition with Entry and Exit above and below Average Labur Productivity, 2003-2007

\begin{tabular}{|c|c|c|c|c|c|c|c|}
\hline \multirow{2}{*}{ Industry } & \multicolumn{2}{|c|}{ Surviving Firms } & \multicolumn{2}{|c|}{ Entering Firms } & \multicolumn{2}{|c|}{ Exiting Firms } & \multirow[b]{2}{*}{$\Delta \Pi_{I}$} \\
\hline & $\Delta \overline{\boldsymbol{\pi}}_{C}$ & $\Delta \operatorname{cov}_{C}$ & Above avg & Below avg & Above avg & Below avg & \\
\hline Mining and Quarrying, Electricity, gas and water supply & -0.140 & -0.080 & 0.006 & -0.005 & -0.013 & 0.123 & -0.110 \\
\hline Manufacture of food, beverages and tobacco & 0.040 & -0.020 & 0.005 & -0.006 & -0.038 & 0.040 & 0.030 \\
\hline Manufacture of textile and leather products & 0.060 & 0.130 & 0.002 & -0.002 & -0.003 & 0.020 & 0.200 \\
\hline Manufacture of wood products & -0.020 & 0.120 & 0.001 & -0.002 & -0.003 & 0.006 & 0.100 \\
\hline Manufacture of pulp, paper and printing & -0.050 & 0.020 & 0.001 & -0.005 & -0.024 & 0.009 & -0.040 \\
\hline Manufacture of chemicals & -0.110 & 0.150 & 0.002 & -0.002 & -0.014 & 0.033 & 0.060 \\
\hline Manufacture of rubber & 0.060 & 0.080 & 0.000 & -0.001 & -0.007 & 0.020 & 0.150 \\
\hline Manufacture of non-metallic minerals & 0.010 & 0.130 & 0.001 & -0.003 & -0.052 & 0.005 & 0.100 \\
\hline Manufacture of basic metals and fabricated metal products & 0.030 & 0.140 & 0.001 & -0.003 & -0.007 & 0.007 & 0.180 \\
\hline Manufacture of machinery and equipment NEC & 0.100 & 0.060 & 0.003 & -0.003 & -0.028 & 0.028 & 0.170 \\
\hline Manufacture of electrical and optical equipment & 0.120 & 0.100 & 0.007 & -0.001 & -0.022 & 0.024 & 0.230 \\
\hline Manufacture of transport equipment & 0.100 & 0.190 & 0.000 & -0.002 & -0.006 & 0.005 & 0.280 \\
\hline Manufacturing NEC & -0.010 & 0.210 & 0.006 & -0.004 & -0.003 & 0.004 & 0.190 \\
\hline Construction & -0.020 & 0.040 & 0.005 & -0.004 & -0.017 & 0.018 & 0.020 \\
\hline Sale, maintenance and repair of motor vehicles & 0.040 & 0.040 & 0.002 & -0.004 & -0.022 & 0.016 & 0.070 \\
\hline Wholesale trade & 0.120 & 0.050 & 0.003 & -0.005 & -0.016 & 0.031 & 0.190 \\
\hline Retail trade & 0.000 & 0.130 & 0.001 & -0.002 & -0.004 & 0.016 & 0.150 \\
\hline Hotels and restaurants & -0.070 & 0.210 & 0.007 & -0.011 & -0.008 & 0.013 & 0.140 \\
\hline Transport and storage & 0.000 & 0.200 & 0.002 & -0.002 & -0.015 & 0.013 & 0.200 \\
\hline Post and telecommunication & 0.120 & 0.210 & 0.003 & -0.001 & -0.026 & 0.047 & 0.360 \\
\hline Real estate & -0.040 & 0.120 & 0.007 & -0.011 & -0.022 & 0.032 & 0.080 \\
\hline Renting of machinery and equipment & 0.040 & 0.030 & 0.001 & -0.002 & -0.044 & 0.010 & 0.040 \\
\hline Computing and related activities & 0.020 & 0.120 & 0.003 & -0.009 & -0.008 & 0.015 & 0.140 \\
\hline R\&D and other business services & 0.050 & 0.110 & 0.007 & -0.017 & -0.052 & 0.042 & 0.140 \\
\hline TOTAL ECONOMY & 0.030 & 0.100 & 0.004 & -0.008 & -0.028 & 0.026 & 0.120 \\
\hline
\end{tabular}


Table B7. FHK Decomposition by Sector, 1998-2002 (employment weights)

\begin{tabular}{lcccccc}
\hline \multicolumn{1}{c}{ Industry } & within & between & cross & entry & exit & CH Ip98-02 \\
\hline Mining and quarrying, Electricity, gas and water supply & 0.12 & -0.01 & -0.14 & 0.00 & 0.00 & -0.02 \\
Manufacture of food, beverages and tobacco & 0.16 & 0.05 & -0.16 & -0.01 & -0.03 & 0.08 \\
Manufacture of textile and leather products & 0.11 & 0.11 & -0.11 & 0.00 & -0.02 & 0.12 \\
Manufacture of wood products & 0.13 & 0.08 & -0.09 & 0.00 & 0.01 & 0.12 \\
Manufacture of pulp, paper and printing & 0.02 & 0.28 & -0.29 & 0.00 & -0.01 & 0.01 \\
Manufacture of chemicals & 0.10 & 0.05 & -0.12 & -0.01 & -0.01 & 0.03 \\
Manufacture of rubber & -0.01 & 0.06 & -0.06 & 0.00 & -0.02 & 0.01 \\
Manufacture of non-metallic minerals & 0.18 & 0.11 & -0.18 & 0.00 & 0.00 & 0.11 \\
Manufacture of basic metals and fabricated metal products & 0.14 & 0.11 & -0.12 & 0.00 & -0.01 & 0.13 \\
Manufacture of machinery and equipment NEC & -0.01 & -0.07 & 0.02 & 0.00 & -0.01 & -0.05 \\
Manufacture of electrical and optical equipment & 0.09 & 0.12 & -0.08 & 0.00 & -0.01 & 0.14 \\
Manufacture of transport equipment & -0.29 & 0.25 & -0.05 & 0.02 & 0.01 & -0.08 \\
Manufacturing NEC & 0.06 & 0.08 & -0.17 & 0.00 & 0.00 & -0.02 \\
Construction & -0.03 & 0.26 & -0.27 & -0.01 & -0.08 & 0.03 \\
Sale, maintenance and repair of motor vehicles & 0.13 & -0.02 & -0.01 & 0.00 & 0.00 & 0.10 \\
Wholesale trade & 0.08 & 0.16 & -0.13 & 0.00 & 0.00 & 0.10 \\
Retail trade & -0.07 & 0.11 & -0.09 & 0.00 & -0.01 & -0.04 \\
Hotels and restaurants & 0.08 & 0.05 & -0.21 & -0.01 & 0.02 & -0.11 \\
Transport and storage & 0.09 & 0.08 & -0.20 & 0.00 & -0.01 & -0.01 \\
Post and telecommunications & 0.11 & 0.13 & -0.09 & -0.02 & -0.02 & 0.14 \\
Real estate & 0.03 & 0.17 & -0.25 & -0.15 & -0.05 & -0.15 \\
Renting of machinery and equipment & 0.29 & 0.22 & -0.25 & 0.00 & 0.01 & 0.25 \\
Computing and related activities & 0.08 & 0.05 & -0.01 & -0.01 & 0.00 & 0.11 \\
R\&D and other business services & 0.28 & 0.19 & -0.35 & 0.01 & -0.05 & 0.18 \\
\hline TOTAL ECONOMY & 0.07 & 0.10 & -0.17 & 0.00 & -0.02 & 0.01 \\
\hline
\end{tabular}

Source: ARD \& BSD, authors' calculations

Table B8. FHK Decomposition by Sector, 2003-2007 (employment weights)

\begin{tabular}{lcccccc}
\hline \multicolumn{1}{c}{ Industry } & within & between & cross & entry & exit & CH Ip03-07 \\
\hline Mining and quarrying, Electricity, gas and water supply & -0.21 & 0.18 & -0.16 & 0.00 & -0.09 & -0.11 \\
Manufacture of food, beverages and tobacco & 0.11 & -0.04 & -0.04 & 0.00 & 0.00 & 0.03 \\
Manufacture of textile and leather products & 0.25 & 0.12 & -0.19 & 0.00 & -0.02 & 0.20 \\
Manufacture of wood products & 0.07 & 0.08 & -0.05 & 0.00 & 0.00 & 0.10 \\
Manufacture of pulp, paper and printing & -0.02 & 0.04 & -0.05 & 0.00 & 0.01 & -0.04 \\
Manufacture of chemicals & 0.03 & 0.08 & -0.07 & 0.00 & -0.02 & 0.06 \\
Manufacture of rubber & 0.16 & 0.06 & -0.08 & 0.00 & -0.01 & 0.15 \\
Manufacture of non-metallic minerals & 0.08 & 0.10 & -0.03 & 0.00 & 0.04 & 0.10 \\
Manufacture of basic metals and fabricated metal products & 0.18 & 0.07 & -0.07 & 0.00 & 0.00 & 0.18 \\
Manufacture of machinery and equipment NEC & 0.16 & 0.05 & -0.04 & 0.00 & 0.00 & 0.17 \\
Manufacture of electrical and optical equipment & 0.20 & 0.08 & -0.07 & 0.01 & 0.00 & 0.23 \\
Manufacture of transport equipment & 0.26 & 0.05 & -0.04 & 0.00 & 0.00 & 0.28 \\
Manufacturing NEC & 0.13 & 0.13 & -0.06 & 0.00 & 0.00 & 0.19 \\
Construction & 0.05 & 0.11 & -0.15 & 0.00 & 0.00 & 0.02 \\
Sale, maintenance and repair of motor vehicles & 0.13 & 0.07 & -0.12 & 0.00 & 0.01 & 0.07 \\
Wholesale trade & 0.20 & 0.07 & -0.09 & 0.00 & -0.01 & 0.19 \\
Retail trade & 0.08 & 0.19 & -0.13 & 0.00 & -0.01 & 0.15 \\
Hotels and restaurants & 0.15 & 0.12 & -0.14 & 0.00 & 0.00 & 0.14 \\
Transport and storage & 0.18 & 0.08 & -0.06 & 0.00 & 0.00 & 0.20 \\
Post and telecommunications & 0.26 & 0.02 & 0.06 & 0.00 & -0.02 & 0.36 \\
Real estate & 0.03 & 0.12 & -0.08 & 0.00 & -0.01 & 0.08 \\
Renting of machinery and equipment & 0.07 & 0.07 & -0.07 & 0.00 & 0.03 & 0.04 \\
Computing and related activities & 0.13 & 0.06 & -0.05 & 0.00 & -0.01 & 0.14 \\
R\&D and other business services & 0.24 & 0.21 & -0.30 & -0.01 & 0.01 & 0.14 \\
\hline TOTAL ECONOMY & 0.15 & 0.11 & -0.13 & 0.00 & 0.00 & 0.12 \\
\hline
\end{tabular}

Source: ARD \& BSD, authors' calculations 
Table B9. FHK Decomposition by Sector, 1998-2007 (employment weights)

\begin{tabular}{|c|c|c|c|c|c|c|}
\hline Industry & within & between & cross & entry & exit & CH Ip98-07 \\
\hline Mining and quarrying, Electricity, gas and water supply & 0.04 & -0.05 & -0.11 & 0.00 & 0.07 & -0.18 \\
\hline Manufacture of food, beverages and tobacco & 0.12 & -0.13 & -0.11 & -0.01 & -0.09 & -0.03 \\
\hline Manufacture of textile and leather products & 0.49 & 0.22 & -0.30 & 0.02 & -0.04 & 0.46 \\
\hline Manufacture of wood products & 0.15 & 0.25 & -0.21 & 0.00 & 0.01 & 0.19 \\
\hline Manufacture of pulp, paper and printing & 0.08 & 0.28 & -0.26 & 0.00 & -0.02 & 0.12 \\
\hline Manufacture of chemicals & 0.07 & 0.06 & -0.06 & 0.00 & 0.01 & 0.07 \\
\hline Manufacture of rubber & 0.17 & 0.11 & -0.11 & 0.01 & -0.03 & 0.20 \\
\hline Manufacture of non-metallic minerals & 0.21 & 0.22 & 0.00 & 0.01 & 0.02 & 0.41 \\
\hline Manufacture of basic metals and fabricated metal products & 0.22 & 0.11 & -0.11 & 0.01 & -0.02 & 0.25 \\
\hline Manufacture of machinery and equipment NEC & 0.31 & 0.15 & -0.08 & 0.01 & -0.02 & 0.41 \\
\hline Manufacture of electrical and optical equipment & 0.43 & 0.16 & -0.10 & 0.02 & 0.02 & 0.49 \\
\hline Manufacture of transport equipment & 0.37 & 0.23 & -0.12 & 0.02 & -0.01 & 0.53 \\
\hline Manufacturing NEC & 0.17 & 0.08 & -0.09 & 0.02 & -0.01 & 0.19 \\
\hline Construction & 0.05 & 0.30 & -0.24 & 0.01 & -0.06 & 0.19 \\
\hline Sale, maintenance and repair of motor vehicles & 0.22 & 0.01 & 0.03 & 0.01 & -0.04 & 0.32 \\
\hline Wholesale trade & 0.32 & 0.20 & -0.16 & 0.01 & 0.01 & 0.36 \\
\hline Retail trade & 0.02 & 0.16 & -0.08 & 0.00 & -0.02 & 0.13 \\
\hline Hotels and restaurants & 0.11 & 0.05 & -0.11 & -0.02 & 0.01 & 0.02 \\
\hline Transport and storage & 0.16 & 0.14 & -0.24 & 0.01 & -0.04 & 0.11 \\
\hline Post and telecommunications & 0.27 & 0.12 & 0.02 & 0.01 & 0.04 & 0.38 \\
\hline Real estate & 0.12 & 0.11 & -0.16 & -0.04 & -0.05 & 0.08 \\
\hline Renting of machinery and equipment & 0.19 & 0.24 & -0.22 & 0.00 & 0.00 & 0.20 \\
\hline Computing and related activities & 0.18 & 0.12 & -0.03 & -0.01 & -0.04 & 0.30 \\
\hline$R \& D$ and other business services & 0.38 & 0.43 & -0.53 & 0.01 & -0.07 & 0.36 \\
\hline TOTAL ECONOMY & 0.20 & 0.15 & -0.20 & 0.00 & -0.01 & 0.16 \\
\hline
\end{tabular}

Source: ARD \& BSD, authors' calculations 